Revista de Estudios Histórico-Jurídicos

[Sección historia del derecho canónico]

XLI (Valparaíso, Chile, 2019)

[pp. 113 - 139]

\title{
CONCUBINOS Y ADMISIÓN A LOS SACRAMENTOS EN EL IUS ANTIQUUM: A PROPÓSITO DE ALGUNAS EXCEPCIONES EN LAS FUENTES CANÓNICAS
}

\author{
[Concubines And Acceptance In Sacrements In Ius Antiquum: Regarding \\ Some Exceptions In Canonical Sources]
}

\author{
JAVIER BELDA INIESTA* \\ Universidad Católica de Murcia, España
}

\begin{abstract}
RESUMEN
El objetivo de este estudio es ofrecer un análisis histórico y jurídico de fuentes canónicas del ius antiquum sobre el concubinato y la admisión de quienes se encontraban en dicha situación a los sacramentos. A través de una lectura utroquística de las fuentes y del contexto histórico, social y jurídico relacionado, se propondrá una revisión historiográfica del tema, demostrando que la admisión de los concubinos a los sacramentos no constituye una forma de abuso o de traición a la Tradición; por el contrario, las fuentes analizadas constituyen un testimonio de la capacidad de la Iglesia del primer milenio -cuyas aspiraciones no distan mucho de las de la Iglesia actualde comprender en un diálogo armonioso entre la Justicia y la Misericordia los problemas y las inquietudes presentes en la sociedad de un determinado momento histórico, teniendo siempre como objetivo de su acción de gobierno el bienestar social y espiritual de la comunidad de fieles.
\end{abstract}

\section{Palabras clave}

Concubinato, admisión a los sacramentos, ius antiquum, concilios ecuménicos, concilios provinciales y locales, sí $\alpha \mu \rho \varsigma$

\section{ABSTRACT}

This study aims at offering a historical and legal analysis of canonical sources of the ius antiquum on concubinage and the acceptance of those who were in that situation to participate in sacraments. By reading Utraquist writings of the historical, social and legal sources and contexts, a historiographical analysis on this subject will be presented, demonstrating that the acceptance of concubines in sacraments is not a type of abuse or betray to the Tradition; on the contrary, the analysed sources are a testimony of the capacity of the Church of the first millennium-whose aspirations are not too different from the modern Church- to understand, by means of a harmonious dialogue between Justice and Mercy, the problems and concerns of the society of a particular historical time, always making the social and spiritual well-being of the community of the faithful as a governance objective.

\section{KEYWORDS}

Concubinage, acceptance in sacraments, ius antiquum, ecumenical councils, provincial and local councils, si $\gamma \alpha \mu о \varsigma$

ReCIBIDO el 12 de marzo de 2019 y ACEPTADO el 4 de junio de 2019

* Profesor ordinario de Historia del Derecho y de las Fuentes Canónicas. E-mail: jbelda@ ucam.edu 


\section{INTRODUCCIÓN}

En los últimos años, acaso por los cambios sufridos en el contexto social, ha aumentado la atención de los estudiosos de ámbito eclesiástico en torno a la situación en la que se encuentran los cónyuges separados, los divorciados y los nuevamente casados, así como el tratamiento pastoral que debe darse a las uniones civiles, a los convivientes y a las familias de hecho, agrupándolos a todos ellos tradicionalmente en las llamadas "situaciones irregulares". Sin embargo, cada una de estas situaciones, acaso por la enorme diferencia de circunstancias que las rodean, debe ser afrontada de modo diferenciado, especialmente cuando, desde el punto de vista canónico, se trata la cuestión del acceso a los sacramentos ${ }^{1}$.

Probablemente, de entre todas ellas, la más compleja de tratar es la de los divorciados vueltos a casar civilmente, ya sea desde el punto de vista teológicopastoral, ya desde el canónico, siendo el objeto principal de debate durante la reciente XVI Asambla General Ordinaria del Sínodo de los Obispos², a la que siguió la exhortación apostólica postsinodal del papa Francisco Amoris Laetitia, sobre el amor de la familia, de 19 de marzo de 2016. El Santo Padre, al referirse a estas situaciones, recuerda la ayuda que debe ofrecerse para que, aún en tales condiciones, se pueda vivir en Gracia, lo que requiere, necesariamente, la colaboración de la Iglesia ${ }^{3}$. Lógicamente, la vida de Gracia implica una vida de Sacramentos, de ahí que el propio pontífice haya evidenciado que dicha ayuda

${ }^{1}$ Véase, entre la literatura más reciente, BeLardinelli, Sergio, Diciamoci la verità: non è tutto una favola: il Cristianesimo e le sfide del tempo presente (Siena, Cantagalli, 2015); BourGES, Béatrice, Catholique divorcée remariée (Paris, Artège, 2015); CerETI, Giovanni, Matrimonio e misecordia: divorzio, nuove nozze e prassi della Chiesa (Bologna, Edizioni Dehoniane, 2015); Cormier, Philippe, Les irréguliers de l'amour: une question pour l'Église (Paris, Cerf, 2015); Dugan, Patricia, Navarro, Luis, Mercy and law in marriage (Montreal, Wilson \& Lafleur, 2015); Falcone, Francesco Andrea; Ferrari, Enzo, Dallo scandalo alla carezza: separati, divorziati e Chiesa (Milano, Edizioni Paoline, 2015); Gentili, Paolo, Cioncolini, Tommaso, Cerioni, Giulia, Luci di speranze per le famiglie ferite: accanto alle coppie in crisi, ai separati, ai divorziati e ai conviventi (Cinisello Balsamo, San Paolo, 2015); Granados, José, Eucaristia e divorzio: cambia la dottrina? Saggio sulla fecondità dell'insegnamento cristiano (Siena, Cantagalli, 2015); SÁnChez Navarro, Luis, Cosa ne pensa Gesù dei divorziati risposati? Una luce dimenticata per la discussione attuale (Siena, Cantagalli, 2015); Tettamanzi, Paola, Ancora famiglia; Genitori sempre: la prima ricerca con le associazioni dei separati (Cinisello Balsamo, San Paolo, 2015); DE FILIPPIS, Bruno, É caduto il muro tra chiesa e divorziati? (Pisa, Pacini Editore, 2016); DiRIART, Alexandra, Divorziati risposati e comunione spirituale (Siena, Cantagalli, 2016); GugLIELMONI, Luigi; Negri, Fausto, Separati, divorziati e risposati nella Chiesa: alla luce della "Amoris laetitia" di papa Francesco (Torino, Elledici, 2016); Medina Balam, Mario, Pueden comulgar los divorciados vueltos a casar? Análisis de la norma canónica a la luz de "Amoris laetitia" (México, Buena Prensa, 2017); Ометто, Matteo, Divorziati che vivono una nuova unione nella Chiesa cattolica: da Familiaris consortio ad Amoris laetitia (Padova, 2018).

${ }^{2}$ Cfr. Relazione finale del Sinodo dei Vescovi al Santo Padre Francesco (24 ottobre 2015), nn. 84-86.

3 "A causa de los condicionamientos o factores atenuantes es posible que, en medio de la situación objetiva de pecado -que no sea subjetivamente culpable o que no lo sea de modo pleno- se pueda vivir en gracia de Dios, se pueda amar, y también se pueda crecer en la vida de la gracia y de la caridad, recibiendo para ello la ayuda de la Iglesia” (n. 305). 
"en ciertos casos podría ser también la ayuda de los sacramentos" la Reconciliación y la Eucaristía

Sin embargo, y aunque pueda parecer novedoso por los términos en los que se plantean, no es, ni mucho menos, la primera vez que se reflexiona sobre el particular, tanto en lo que atañe al trato pastoral que se debe dispensar a quienes se encuentran en estas situaciones como a su acceso a los Sacramentos.

Desde su fundación, la Iglesia -que ha recibido el Depósito de la Fe para anunciarlo a los hombres sin que sufriera variación- ha debido afrontar el retraso de la parusía, aprendiendo a hacer presente a cada tiempo el mensaje salvífico de Cristo, intentando que éste llegase a todos, tantos a justos como injustos, evitando así que la Historia Salutis dejase fuera aquéllos que podían encontrarse en la periferia de una Iglesia naciente que poco a poco cobraba conciencia de su propia identidad. En este sentido, los cánones conciliares, la doctrina de los Padres de la Iglesia y la legislación sobre la conducta de los fieles mostraron una sensibilidad excepcional a la realidad social de cada tiempo, de modo que, aun manteniendo firme determinados preceptos de raíz escriturística y de los cuales no podía separarse, demostró que, llegado el extremo, el sábado estaba hecho para el hombre y no el hombre para el sábado ${ }^{6}$.

De hecho, en las fuentes canónicas del primer milenio se puede rastrear cómo aquellos que tenían a su cargo el gobierno de las comunidades y su cuidado pastoral trataron con cierta frecuencia la cuestión de las uniones rotas y de cómo afrontar como comunidad tanto al causante, si lo hubiere, como a las víctimas que, por desgracia, siempre la hay, ofreciéndonos un rosario de excepciones y de actuaciones particulares que, si bien no son norma general, no dejan de ser relevantes pues -con las debidas salvedades- podrían llegar a servir para iluminar situaciones actuales.

Desde el punto de vista científico, como decíamos, la doctrina ha vuelto en los últimos años con mayor recurrencia sobre el argumento ${ }^{7}$, especialmente a partir

${ }^{4}$ Ibíd., n. 351.

${ }^{5}$ Para ello, los cónyuges deberían demostrar dos condiciones fundamentales: por un lado, el deseo de cambiar de situación y, por otro, la imposibilidad manifiesta de hacerlo. Evidentemente, corresponde a la Iglesia verificar la coexistencia real de ambas condiciones, lo que implica, desde el punto de vista canónico, una dificultad manifiesta, pues la primera condición pertenece al foro interno y la segunda implica valorar hasta qué punto es imposible poner en práctica ese deseo interior.

${ }^{6} \mathrm{La}$ fragilidad humana, y la posibilidad de que sus uniones sucumbieran al mundo y al pecado, ha azotado desde el comienzo de los tiempos al ser humano, y a pesar de haber conocido plenamente la Revelación en Cristo, no siempre ha podido hacerse presente en su darse al otro como Cristo lo hace con su Iglesia (Cfr. Ef. 5: 25-30).

${ }^{7}$ Si bien puede haber aumentado la literatura científica al repecto, nunca ha dejado de reflexionarse sobre el particular. La cuestión de la porneia mateana, por ejemplo, fue discutida por Hilario, Agustín o Erasmo, cfr. PELland, Gilles, La práctica de la Iglesia antigua relativa a los fieles divorciados y vueltos a casarse, en CDF, Atención pastoral de divorciados vueltos a casar (Madrid, 2003), p. 112; las segundas nupcias en la patrística fue discusión habitual, cfr. HunTER, David, Did the Early Church absolutely forbid remarriage after divorce?, en Vergentis, 6 (2018), pp. 45-64; Bof, Riccardo; Leyser, Conrad, Divorce and Remarriage CoOper, Kate (ed.), between Late Antiquity and the Early Middle Ages: Canon Law and Conflict Resolution, en 
de la novedad que supuso el Vaticano $\mathrm{II}^{8}$, viendo la luz algunas obras que, acaso yendo mucho más allá de lo que las fuentes históricas podían decirnos ${ }^{9}$, llegaron a arriesgar algunos elementos fundamentales de la unión sacramental -como la indisolubilidad inherente al matrimonio- so capa de acercarse a las situaciones de dolor que contemplaban y que exigían una respuesta. Esta postura fue contestada inmediatamente después como falsamente integradora, al sostenerse sobre argumentos excesivamente vagos e imprecisos ${ }^{10}$.

Ahora bien, al margen de discusiones doctrinales, que, sin realizar un estudio directo de las fuentes, suponen acaso un intento de utilización de las mismas para sostener el propio parecer, lo cierto es que, si bien la prohibición de las segundas

Cooper, Kate (ed.) Making Early Medieval Societies: Conflict and Belonging in the Latin West, 300-1200, (Cambridge, 2016); y fue también objeto de debate durante el Concilio de Trento, cfr. BRESSAN, Luigi, II canone tridentino sul divorzio per adulterio e l'interpretazione degli autori (Roma, 1973), pp. 35-50. A su vez, el tema concetró diversos estudios en años anteriores al último Sínodo, cfr. LuÑo Rodríguez, Ángel, L'epicheia nella cura pastorale dei fedeli divorziati e risposati, en L'Osservatore Romano (Ciudad del Vaticano, 26/11/97); Botero Giraldo, José Sílvio, Divorciados vueltos a casa. Un problema humano, una tradiciòn ecclesial, una perspectiva de futuro (Bogota, San Pablo, 2002); VIDAL, Marciano, Propuestas para una "normalización" eclesial de las parejas católicas "recasadas", en Moralia, 29 (2006), pp. 83-110; Mazzola, Lia, L'evoluzione della normativa ecclesiale, en Quale comunione? Divorziati risposati e sacramenti, (Roma, 2009), pp. 28-40; PETRA, Basilio, Welcoming Divorced and Remarried Persons. A Formal Proposal, en International Academy for Marital Spirituality Review, 20 (2014), pp. 138-144; ÉL MISMO, Motives for Marriage. Reflections from an Ethical-Theological Perspective», en International Academy for Marital Spirituality Review, 13 (2007), pp. 38-40; ÉL MISMO, The Divorced and Remarried. A New State within the Church?, en International Academy for Marital Spirituality Review, 16 (2010), pp. 194-207.

${ }^{8} \mathrm{La}$ novedad desde el punto de vista pastoral, no referida en concreto a la cuestión de las nuevas nupcias, si bien en el propio concilio surgió la discusión. Cfr. Wenger, Antoine, Vatican II. Chronique de la quatrième session (Paris, 1966), pp. 200-246.

${ }^{9}$ La primera de ellas fue Pospishit, Victor, Divorce and Remarriage. Towards a New Catholic Teaching (Nueva York, 1967), y la segunda, y acaso la que más contestación ha provocado, tanto por lo lejos que llega a ir como por la interpetación del canon 8 de Nicea, fue la obra de CERETI, Giovanni, Divorzio, nuove nozze e penitenza nella Chiesa primitiva (Roma, 2013); ÉL MISMO, Matrimonio e indissolubilità: nuove prospettive (Bologna, 1971); Él mismo, Giudici o Consiglieri?, en Concilium, 86 (1973), pp. 121-135. Es también interesante la postura de MoINGT, Joseph, Le divorce pour motif d'impudicité, en Recherche de science rel, 56 (1968), pp. 337-384, que indica que sólo Jerónimo y Agustín se oponen a las segundas nupcias de la víctima del adulterio.

${ }^{10}$ Así lo calificará Adnès, cfr. ADNÈs, Pierre, De vinculo matrimonii apud Patres, en Vinculum matrimoniale (Roma, 1973), p. 86; ÉL MISMO, De indissolubilitate matrimonii apud Patres: opiniones et observationes, en Periodica de re morali canonica liturgica, 61 (1972), pp. 195-224, a los que pronto se unieron Noonan, John, Novel 22, en The Bond of Marriage. An Ecumenical and Interdisciplinary Study (London, 1968), pp. 41-96. PeLLAND, Gilles, Le dossier patristique relatif au divorce, en Science et Esprit, 25 (1973), pp. 99-119; NAutin, Pierre, L'Eglise primitive face au divorce (Paris, 1971), y en su edición de las homilías de Orígenes: NauTin, Pierre, OrigÉne, Homélies sur Jrmie, (Paris, 1976), o Crouzel, Henri, L'Eglise primitive face au divorce (Paris, 1971); ÉL MISMO, Divorce et remariage dans l'Eglise primitive: quelques reflexions de methodologie historique, en Nouvelle Revue Theologique, 98 (1976) pp. 891-917; ÉL MISMO, Un nouvel essai pour prouver l'acceptation des secondes noces après divorce dans l'Eglise primitive, en Augustinianum, (Dec. 1977); ÉL MISMO, Les “digamoi" visés par le concile de Nicee dans son canon 8, en Augustinianum, (Dec. 1978), p. 566. 


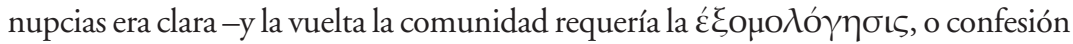
pública $^{11}$-, consideramos interesante estudiar las actuaciones que se separaron de la postura común, y, sobre todo, por qué y en qué contesto lo hicieron. Por ello, intentaremos hacer un recorrido por la cultura jurídica de las fuentes canónicas que recogen dichas excepciones en el ius antiquum, empleando los principios de la escuela utroquística para intentar arrojar algo de luz al argumento.

\section{LA DOCTRINA CONCILIAR}

\section{El canon 8 de Nicea y los $\delta \dot{\gamma} \gamma \alpha \mu \mathrm{O}$}

A pesar de la opinión más o menos común con que los Padres de la Iglesia de Oriente y Occidente tratan el tema de las segundas nupcias y la admisión a los sacramentos de los concubinos ${ }^{12}$, no fue extraño que algunas excepciones encontrasen acomodo cuando la doctrina alcance rango canónico y universal en las reuniones conciliares, las cuales fueron extremadamente sensibles a esta situación desde el primer momento, por lo que resulta de gran claridad la consulta de algunas de las más relevantes aportaciones en el marco de los concilios. Sin embargo, una advertencia preliminar nos debe alertar sobre la forma de interpretar los cánones conciliares, y es que siempre se deben leer en su contexto, dada la enorme dificultad que supone para nuestra mentalidad contemporánea alcanzar su verdadero sentido, así como la problemática que implica el acceso a unas fuentes fidedignas.

El can. 8 de Nicea contempla la readmisión de los llamados catharoi (puros) -habitualmente identificados con los novacianos-opuestos a la readmisión tanto de apóstatas como de adúlteros: "De his qui se catharos, id est puros quandoque nominant, ad catholicam autem et apostolicam ecclesiam accedunt, sanctae magnae sinodo visum est, ut impositis eis manibus sic in clero maneant. Ante omnia autem hoc in scriptis ipsos profiteri convenit, quod adhaerebunt et sequentur catholicae ecclesiae decreta id est quae et cum digamis communicabunt, et cum iis qui in persecutione lapsi sunt, in quibus et tempus constitutum est, et opportunitas praefinita, ut ipsi sequantur in omnibus ecclesiae decreta. Ubi ergo omnes sive in vicis, sive in urbibus ipsi soli inveniuntur ordinati, qui inveniuntur in clero, erunt in eodem ordine. Si autem catholicae ecclesiae episcopo vel presbytero existente accedunt aliqui, clarum est, quod ecclesiae quidem episcopus episcopi degnitatem habebit: qui autem apud eos, qui cathari dicuntur, nominatur episcopus, presbyteri honorem habebit: nisi utique episcopo placeat ipsum nominis honorem impertire. Si autem hoc illi non placeat, vel chorepiscopi, vel presbyteri locum excogitabit, ut esse omnino in clero videatur, ne in civitate duo sint episcopi"13.

No es difícil saber a quiénes se refiere al hablar de los caídos durante la perse-

${ }^{11}$ Cfr. Tertullianum, De paenitentia, en Migne, Jacques Paul (a cura di), Patrologia Latina 1, pp. 1243-1248. En adelante: Migne, Patrologia Latina.

${ }^{12}$ Rincón PÉREZ, Tomás, La doctrina sobre la indisolublidad del matrimonio del matrimonio en el primer milenio cristiano, en Ius Canonicum, 13/1 (1973), pp. 91-136, esp. pp. 100-102.

${ }^{13}$ Concilium Niceanum (a. 325), can. 8, en Mansi, Giovanni Domenico (a cura di), Sacrorum Conciliorum nova et amplissima collectio, 2, [rist.] (Graz, 1960), col. 671B-C-D. En adelante: MANSI, Sacrorum. 
cución: los violentos ataques contra los cristianos de finales del siglo III hicieron que muchos apostatasen por miedo a perder su vida. Sin embargo, es mucho más compleja la interpretación del término đí $\gamma \alpha \mu \mathrm{\alpha}$. La inclusión de ambas categorías en el mismo canon dificulta aún más su comprensión: pese a que obliga a los llamados puros a aceptar nuevamente ambos, a unos les exige hacer penitencia pública mientras que nada se dice para los casados nuevamente.

La cuestión, sin embargo, no atañe a la pena impuesta a los vueltos a casar, sino exactamente a quiénes se refiere. Algunos lo interpretan como aquel que tiene dos mujeres o dos vínculos simultáneos, y otros afirman que se debe entender simplemente el matrimonio de los viudos, que también será negado por parte de la literatura de la época, mereciendo incluso algún reproche conciliar, como veremos después. De hecho, la Iglesia tardará mucho en dar un reconocimiento pleno a esta última situación, pues antes le daba la consideración de una variedad de adulterio: Atenágoras, de hecho, lo calificaba de decorum adulterium ${ }^{14}$. Esa consideración fue común durante toda la época conciliar antigua ${ }^{15}$, si bien las restricciones reales a las segundas nupcias fueron dirigidas más bien a los clérigos o a sus viudas ${ }^{16}$ que al resto de la población -exceptuando a la viuda del rey-y son abundantes los formularios de tales uniones ${ }^{17}$.

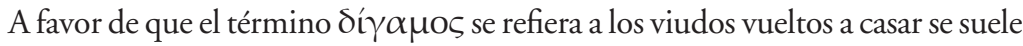
emplear un texto de San Jerónimo, en el que leemos: "qui de monogamia sacerdos est, quare viduam hortatur ut $\delta$ i $\alpha \mu \rho \zeta$ sit?" ${ }^{18}$. Sin embargo, no podemos obviar que el texto de San Jerónimo es un siglo posterior al canon conciliar en concreto, con lo que estaríamos tan cerca del texto de Atenágoras como del escrito por el santo eremita occidental.

No está tan claro que la referencia sea necesariamente al matrimonio de las viudas, ni que dicha advertencia vaya dirigida a quienes rechazaban esta segunda unión, pues en la legislación conciliar más rigorista, como veremos después, se impone pena a la viuda, pero probablemente para castigar su unión previa a un vínculo matrimonial estable.

Ni siquiera el texto que tradicionalmente se ha utilizado como más esclarecedor para la correcta interpretación del término (el cuarto parágrafo de la vigésima homilía sobre Jeremías) resulta indiscutible: Pierre Nautin defenderá que se trata de la cuestión de las segundas nupcias de las viudas ${ }^{19}$, mientras que Luciana Mortari

${ }^{14}$ Cfr. Athenagoras Atheniensis, Legatio pro Christianis, 33, en Migne, Jacques Paul (a cura di), Patrologia Graeca 6, col. 967: "[...] quisque vel ut natus est, maneat, vel unicis in nuptis. Secundae enim decorum adulterium”. En adelante: Minge, Patrologia Graeca.

${ }^{15}$ KInG, Paul, Derecho y sociedad en el reino visigodo (Madrid, 1981), p. 262.

${ }^{16}$ Pardo Fernández, Alejandrina, La condición de viuda en el mundo visigodo, a través de las actas conciliares, en Los visigodos. Historia y civilización. Antigüedad y cristianismo, 3 (1986), p. 210.

${ }^{17}$ Fernández Alonso, Justo, La cura pastoral en la España romano-visigoda (España-Roma, 1955), p. 420.

${ }^{18}$ Sancti Hieronymi, Ep. LII, 16, en Corpus Scriptorum Ecclesiasticorum Latinorum, 54, p. 439.

${ }^{19}$ Nautin, Pierre, OrigÉne, Homélies sur Jrmie, (Paris, 1976), pp. 268-269, notas 1 y 2. 
sostiene que se trata de la cuestión de los divorciados vueltos a casar, apoyándose en la tradición oriental de la Iglesia ${ }^{20}$.

Un punto importante en la discusión es lo que se exige a los rigoristas que hagan

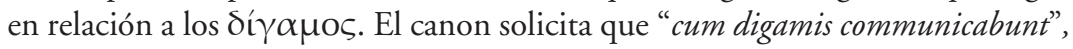

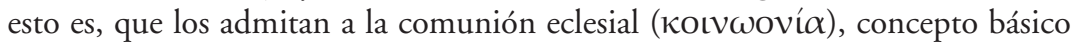
en la eclesiología de la Iglesia primitiva ${ }^{21}$, fuera de la cual no habría lugar para la

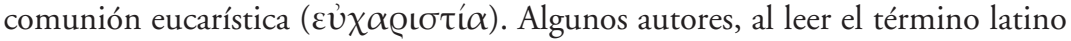
(communio), abundante en otros concilios que se ocupan del mismo asunto, no han hecho distinción entre ambos, lo que, desde el punto de vista canónico, obvia que la exclusión de una u otra comportaba dos penas completamente distintas, como lo son la excomunión parcial -que formaba parte de la penitencia canónica ${ }^{22}-\mathrm{y}$ la total, que no permitía acceder al pecador a la misma ${ }^{23}$.

\section{Los dí $\gamma \alpha \mu \mathrm{o}$ en algunos concilios contemporáneos: Elvira, Ancira y Arlés}

Quizá podría ser útil para aclarar el significado del término la búsqueda del tratamiento canónico dispensado a situaciones similares por algunos concilios contemporáneos a Nicea. Así, si hiciéramos una lectura paralela, por ejemplo, con el can. 72 de Elvira, uno de los más cercanos en el tiempo y que se refiere a las viudas -con todas las salvedades que suponen la problemática de la unidad y las interpolaciones del Concilio iliberritano ${ }^{24}$ - cabría hacerse una pregunta.

${ }^{20}$ Cfr. Mortari, Luciana (cur.), Origene, Omelie su Geremia, (Roma, 1995), p. 265, nota 43.

${ }^{21} 1$ Cor. 1:9, 10, 16-17, etc. Cfr. D’Ercole, Giuseppe, Penitenza canonica sacramentale dalle origini alla pace costantiniana (Roma, 1963), pp. 21-66.

${ }^{22} \mathrm{La}$ é $\xi o \mu o \lambda o ́ \gamma \eta \sigma \iota \varsigma$, o confesión pública. Cfr. Tertullianum, De paenitentia, en Migne, Patrologia Latina 1, col. 1243-1248.

${ }^{23}$ Así lo puso de manifiesto, por ejemplo, Chartier, cfr. CharTier Marie-Clement, La discipline pénitentielle d'après les écrits de saint Cyprien, en Antonianum, 14 (1938), p. 18 y más recientemente Sotomayor, al refutar algunas observaciones realizadas por Vilella en relación al Concilio de Elvira, al que luego nos referiremos. Cfr. Sotomayor Muro, Manuel, Los cánones 1 y 59 del Concilio de Elvira. A propósito de un artículo de J. Vilella Masana, en Polis. Revista de ideas y formas políticas de la Antigüedad Clásica, 19 (2007), pp. 141 ss.

${ }^{24}$ La discusión abierta por Meigne. Cfr. Meigne, Maurice, Concile ou collection d'Elvire?, en Revue d'Histoire Ecclésiastique, 70 (1975), pp. 361-387, dio pie algunos considerasen que se trataba de una simple colección de cánones, acaso la más antigua, pero no de un concilio concreto, cfr. Ramos-Lissón, Domingo, En torno a la autenticidad de algunos cánones del Concilio de Elvira, en Scripta Theologica, 11 (1979), pp. 181-186; Suberbiola MarTínez, Jesús, Nuevos Concilios Hispano-Romanos de los siglos III y IV. La Colección de Elvira (Málaga, 1987), opinión refutada por Sotomayor, Ubiña y Berdugo, cfr. Sotomayor Muro, Manuel, Cristianismo primitivo y paganismo romano en Hispania, en Memorias de Historia Antigua, 5 (1981), p. 178; FernándeZ UBIN̄A, José, Los orígenes del cristianismo hispano: algunas claves sociológicas, en Hispania Sacra, 59/2 (2007), p. 434; Berdugo Villena, Teresa, Fernando de Mendoza "De confirmando concilio iliberritano". Libro 1. Edición, traducción y notas (Granada, 2005). Estos mismos autores abogan por la unidad de los cánones, cfr. Sotomayor Muro, Manuel y Fernández Ubiña, José (a cura di), El concilio de Elvira y su tiempo (Granada, 2005), mientras que otros por la división en tres bloques diferenciados, cfr. Vilella, Josep y Barreda, Pere Enric, ¿Cánones del Concilio de Elvira o cánones pseudoiliberritanos?, en Augustinianum, 46 (2006), pp. 285-373. Para el estado actual de la cuestión, véase LÁZARO SÁNCHEZ, Miguel, L'état actuel de la recherche sur le concile d'Elvire, en Revue des sciences religieuses, 82/4 (2008), pp. 517-546. 
Dicho concilio ha sido considerado tradicionalmente rigorista, dado su carácter eminentemente disciplinar ${ }^{25}$, y es precisamente a éstos a los que va dirigido el canon niceano. Pueden rastrearse elementos comunes con el novacianismo desde el primer canon, con las prohibiciones lanzadas contra lo no practicantes ${ }^{26}$, la defensa del ascetismo y la virginidad (can. 13) o las referencias a los espectáculos (can. 62) ${ }^{27}$. La influencia o, al menos, la postura común, sería, cuando menos, evidente. Como decíamos, una de las posibles interpretaciones del término dí $\gamma \alpha \mu$ os es que se refiera a los viudos vueltos a casar, que no eran admitidos por los rigoristas. Sin embargo, el can. 72 de Elvira, al regular las nupcias de las viudas, sólo las excluye de la comunión eucarística, para cuya admisión prevé posibilidad de penitencia canónica: "Si qua vidua fuerit moechata et eundem postea habuerit maritum, post quinquennii tempus acta legitima poenitentia placuit eam communionem reconciliari. Si alium duxerit relicto illo, nec in fine dandam ei esse communionem, vel si fuerit ille fidelis, quem accepit, communionem non accipiat, nisi post decem annos acta legitima poenitentia, nisi infirmitas coegerit, velocius dare communionem" 28 .

¿Tendría entonces sentido que Nicea pidiera a los rigoristas que admitieran a las viudas a la comunión eclesial, cuando solamente se les había privado de la eucarística? Ciertamente sería aventurarnos demasiado decir que los padres iliberitanos eran novacianistas, pero sí comparten parte del espíritu, probablemente al sufrir la cuestión común de los lapsi, de gran relevancia en la vecina e influyente Cartago, tanto por los apostatas y libellatici-por ejemplo, de Basílides y Marcial $^{29}$ - como la problemática posterior de Donato ${ }^{30}$, sin olvidar que no fueron ajenos a la cuestión de los adúlteros ${ }^{31}$. Así, si comparten con ellos aspectos

${ }^{25}$ GonzÁlez Rivas, Severino, Los castigos penitenciales del Concilio de Elvira, en Gregorianum, 22/2 (1941), pp. 191-214; Menéndez Pelayo, Marcelino, Historia de los heterodoxos españoles (Madrid, 1998), I, p. 96.

${ }^{26}$ FrazeE, Charles, The Origins of Clerical Celibacy in the Western Church, en Church History, 57 Supplement Centennial Issue (1988), pp. 108-126.

${ }^{27}$ Recuérdese, al respecto las obras novacianistas De spectaculis o De bono pudicitiae. Cfr. Blázquez Martínez, José María, La Iglesia Hispana. Orígenes en Lusitania. La venida de Pablo. Los orígenes del cristianismo en Lusitania, en Cuadernos Emeritenses, 4 (2008), pp. 61-100.

${ }^{28}$ Concilium Eliberitanum, a. 305?, en MANSI, Sacrorum 2, [rist.] (Graz, 1960), col. 17. Blazquez y Díaz consideran probada no sólo la procedencia africana de la iglesia hispana, sino su ascendencia como Iglesia Madre. Cfr. Blázquez Martínez, José María, La carta 67 de Cipriano y el origen africano del cristianismo hispano, en Homenaje a Pedro Sainz Rodríguez, III: Estudios históricos, (Madrid, 1986), pp. 93-102; Díaz y DíAZ, Manuel, En torno a los orígenes del cristianismo hispano, en Las raíces de España, (Madrid 1967), pp. 423 ss. Sotomayor se muestra más reticente a tales pruebas, cfr. Sotomayor Muro, Manuel, Reflexión histórico-arqueológica sobre el supuesto origen africano del cristianismo hispano, en II Reunió d'arqueologia paleocristiana hispánica, (Barcelona, 1982), pp. 11 ss.

${ }^{29}$ Cfr. Concilium Africanum II, In causa Basilidis et Martialis, en Mansi, Sacrorum, I, [rist.] (Graz, 1960), coll. 905-906; CaECILII CyprianiI, Epistula LXVII, 1, en CSEL, vol. III, pars I, coll. 735 ss.

${ }^{30} \mathrm{Cfr}$. Optatus Milevitanus Ep., De schismate Donatistarum, I, 16, en Migne, Patrologia Latina 11, coll. 916 ss.

${ }^{31}$ CaECILII Cypriani, Epistula LV, 21, en Corpus Scriptorum Ecclesiasticorum Latinorum, vol. III, pars I, coll. 638-639: "Et quidem apud antecessores nostros quidam de episcopis istic in provincia nostra dandam pacem moechis non putaverunt et in totum poenitentiae locum contra adulteria 
tan relevantes como los referidos a la virginidad, y los desórdenes sexuales son castigados con tanto rigor por los padres conciliares iliberritanos, no cabría que no se persiguiera del mismo modo las segundas nupcias de las viudas si fueran una acción tan reprobable como para merecer la excomunión total, cosa que, sin embargo, no se hace.

El mismo concilio se refiere también a la situación del doble vínculo, en concreto en el can. 9, donde leemos: "Item fidelis femina, quae adulterum maritum reliquerit fidelem et alterum ducit, probibeatur ne ducat. Si autem duxerit, non prius accipiat communionem, quam is, quem relinquit, de saeculo exierit, nisi forte necessitas infirmitatis dare compulerit" 32 . Aquí se excluye de la comunión eucarística al cónyuge inocente que se casara de nuevo hasta que hubiere muerto el primer esposo (el can. 8, que luego veremos, la excluía de la comunión eclesial si no había mediado causa) pero, en lo que a la pena impuesta se refiere, contempla una excepción a la norma general: si bien mientras el cónyuge anterior viva no es posible admitir a la comunión a la que contrajo segundas nupcias, existe una ocasión - por lo demás, de amplia interpretación-en la que se puede ser admitida, lo que implica que había sido excluida sólo de la comunión eucarística y no de la eclesial $^{33}$. No se refiere a que podrá recibir comunión al final de su vida ${ }^{34}$, como

cluserunt. Non tamen a coepiscoporum suorum collegio recesserunt aut catholicae ecclesiae uniatem vel duritiae vel censurae suae obstinatione ruperunt, ut quia apud alios adulteris pax dabatur, qui non dabat de ecclesia separaretur. Manente concordiae vinculo et perseverante catholicae ecclesiae individuo sacramento, actum suum disponit et dirigit unusquisque episcopus rationem propositi sui Domino redditurus".

${ }^{32}$ Cfr. Optatus Milevitanus Ep., De schismate Donatistarum, I, 16, en Migne, Patrologia Latina 11, coll. 916 ss.

${ }^{33}$ García Martínez, al referirse este canon, obvia la segunda parte, refiriendo que "El Concilio de Elvira del año 305, en los cánones 8 y 9, prescribe que las mujeres que dejan a sus maridos sin causa, o por ser adúlteros, y se unen a otros, nec in fine accipiant communionem, a no ser que el marido abandonado haya muerto", pero guardando silencio en cuanto a la excepción que prevé el propio canon. Cfr. GARCíA MARTíneZ, Gumersindo, Indisolubilidad del matrimonio rato y consumado entre dos partes bautizadas (Madrid, 1964), p. 507.

${ }^{34}$ Célebre es la discusión mantenida al respecto entre Sotomayor y Vilella sobre cómo traducir esta expresión en el concilio iliberitano, en la cual, por supuesto, nosotros no entraremos, ya que, para nuestro objetivo, se emplee una traducción ad literam o no, el momento vital al que se refiere es el mismo, y nada tiene que ver con la infirmitas. Para ello, véase VILELla, Josep y Barreda, Pere Enric, ¿Cánones del Concilio de Elvira o cánones pseudoiliberritanos?, en Augustinianum, 46 (2006), pp. 285-373 y la respuesta posterior. SotomaYor Muro, Manuel y Berdugo Villena, Teresa, Traducción de las Actas del Concilio de Elvira. Una respuesta a J. Vilella y P.E. Barreda, en Florentia iliberritana. Revista de estudios de antigüedad clásica, 19 (2008), pp. 383-418, si bien todo arranca de la publicación de Sotomayor Muro, Manuel y Fernández UBIÑA, José (a cura di.), El concilio de Elvira y su tiempo (Granada, 2005), criticando el estudio de Vilella, Josep y Barreda, Pere Enric, Los cánones de la Hispana atribuidos a un concilio iliberritano: estudio filológico, en I concili della cristianita occidentale. Secoli lll-V. XXX. Incontro di studiosi dell'antichita cristiana, Roma, 3-5 maggio 2001 [Studia Ephemeridis Augustinianum 78], (Roma, 2002), pp. 545-579. 
hace en tantas otras ocasiones ${ }^{35}$, sino que emplea el término "infirmitas" 36 (como lo hace también en el canon referido a la viuda sin casarse después) esto es, falta de firmeza, endeblez física. Este término, referido a la mujer, implicaba inconstancia, pusilanimidad ${ }^{37}$, al tiempo que era la consecuencia del pecado original en el alma de fiel ${ }^{38}$. En este sentido, es posible que ambos cánones muestren una cierta piedad y, aceptando la debilidad que acompaña el carácter femenino -según el contexto de la época, obviamente-, ante la asimetría de la situación de la parte inocente (ya por víctima, ya por no tener vínculo previo) evite abandonarla por completo a su suerte. Esta práctica, de marcado acento pastoral -que no doctrinal- no es, como veremos más adelante, ni mucho menos, una excepción en la realidad conciliar de la época.

El canon, por supuesto, no deja de condenar el adulterio, pero ve el remedio saludable que puede ser la comunión en determinados casos, lo que hace su administración sea casi obligada en ciertas ocasiones (“dare compulerit”). Aquí sería necesario comprender mejor qué entendían los padres por falta de firmeza, relevante hasta el punto de obligar a admitir a la adúltera a la comunión eucarística. Además, no obliga al abandono del nuevo cónyuge, ni a la restitución de la relación previa ${ }^{39}$, cosa que si hará en otras ocasiones similares: al referirse a la

${ }^{35}$ Can. 17: "[...] placuit nec in finem eis dandam esse communionem"; can. 10: "Placuit in finem huiusmodi dare communionem"; can. 13: "Placuit eas in finem communionem accipere debere", etc. La expresión nec in finem, por ejemplo, aparece, como indica Sotomayor, 22 veces. Cfr. Sotomayor Muro, Manuel. y Berdugo Villena, Teresa, Traducción, cit., (n. 34), p. 387 , nota 12 .

${ }^{36}$ Infirmitas, en Lexicon totius latinitatis ab Aegidio Forcellini lucubratum, (Padova, 1965), II, pp. 827-828. Especialmente ilustrativo es el modo en que lo emplea Julio César al referirse a los Galos: "His de rebus Caesar certior factus, et infirmitatem gallorum veritus, quod sunt in consillis capiendis mobiles, et novis plerumque rebus student, nihil his committendum existimavit". GAIUS Iulius CAEsar, De bello gallico, 4, 5.

${ }^{37}$ CASTELl, Elizabeth, Virginity and itsmeaning for Women's Sexuality in Early Christianity, en Journal of Feminist Studies in Religion, 2 (1986), pp. 61-68; GARDNER, Jane, Women in Roman Law and Society (Londres, 1986), pp. 14-22; PASTOR De ArozenA, Bárbara, Retórica imperial: el rapto en la legislación de Constantino, en Faventia, 20/1 (1998), p. 77.

${ }^{38}$ ClaEs, Martin y Dupont, Anthony, Augustine's sermons and disability, en LaEs, Christian (ed.), Disability in antiquity, p. 335.

${ }^{39}$ El sínodo cartaginés del 407, retomando las disposiciones de Mileve apenas unos años antes, decía: "Placuit ut, secundum Evangelium et Apostolicam disciplinam, neque dimissus ab uxore neque dimissa a manto alteri coniungatur sed ita maneant ut sibimet reconcilientur. Quodsi contempserint, ad poenitentiam redigantur. In qua causa legem imperialem petendum est promulgar". Cfr. Concilium Milevitanum II, can. 17, en Sacrosanta concilia ad regiam editionem exacta Philip. Labbei et Gab. Cossartii (Pariis, 1671), II, col. 1541 (en adelante, LABBE); Codex Canonum ecclesiae africanae, can. 102, ibíd., col. 1117 (también en Registri EcClesiae CaRTHAgINENSIS eXCerta, can. 102, en Munier, Carlo (a cura di), (Corpus Christianorum, Serie Latina 149, p. 218; Harduinus, Acta Conciliorum et Epistolae Decretales ac Constitutiones SS. Pontificum (Parisiis, 1715), I, col. 923, etc.). Nuevamente García Martínez obvia referirse a la última parte del canon, cfr. García Martínez, Gumersindo, cit. (n. 33), p. 507. Lógicamente, ante todo se invita a la reconciliación, pidiendo que no se unan en nuevo matrimonio ni una parte ni la otra. Pero, otra vez, encontramos cómo los propios padres sinodales prevén la posibilidad, probablemente no extraña, de que sea imposible restaurar la vida común que, incluso en otras ocasiones, llegará a estar expresamente prohibida. 
mujer que habitase con marido ajeno, por ejemplo, si su relación se prolonga hasta la muerte, no podrá ser admitida a la comunión, salvo que lo abandone y cumpla penitencia por diez años (can. 64 $)^{40}$. La misma enmienda se pedirá en el can. $47^{41}$, en el que se prescribe que al que cometiere adulterio muchas veces sólo se le acepte en la comunidad in fine mortis, pero se le dé la comunión si prometiera la enmienda ("si se promiserit cessaturum").

Por lo que respecta al tipo de validez que tenía ese segundo matrimonio al que el canon se refiere ("si autem duxerit"), no podemos obviar que Elvira legisla para un contexto romano, en el que el repudio no era extraño ${ }^{42}$. Al mismo tiempo, la constante diferencia entre parte culpable y no culpable (o de la condición de fiel o de catecúmeno del sujeto), podría interpretarse como la licitud de una segunda unión (sólo para la parte inocente, can. 8), castigando así la esperanza de matrimonio de la parte culpable, lo que no era extraño en la legislación de la época ${ }^{43}$. Esta nueva unión, acaso más concubinaria que matrimonial, podría enlazar con el can. 17 del Concilio de Toledo (año 400), que veremos más adelante, y que permite elegir esposa o concubina, según convenga.

A su vez, puede ser también ilustrativo el can. 10 del otro concilio más cercano en el tiempo al de Nicea, el de Arlés (año 314), acaso el más parecido en el contexto tanto desde el punto de vista interno de la Iglesia como del externo. Cuando la absolución de Ceciliano y la condena de Donato fue contestada, debido al escaso número de jueces que participaron en su decisión ${ }^{44}$, Constantino decidió convocar un Concilio en el que participaran más obispos, y así lo justifica el emperador en la

${ }^{40}$ Concilium Eliberitanum, en MANsi, Sacrorum, 2, [rist.] (Graz, 1960), col. 13.

${ }^{41}$ Ibíd.

${ }^{42}$ Tejada y Ramiro, Juan, Colección de cánones y de todos los concilios de la iglesia de España $y$ de América (en latín y castellano) (Madrid, 1850), II, p. 45. Ciertamente, para el judío tampoco era extraño, pero hacía ya demasiado tiempo que el cristianismo había abandonado el contexto hebreo, con la ruptura entre las comunidades cristianas y judías después del concilio hebreo-fariseo de Jamnia del año 70, que expulsa formalmente a las comunidades cristianas, excluyéndolas de las sinagogas, y abriendo el camino a la consolidación del modelo eclesial paulino. Cfr. Duchesse, Louis, Early History of Christian Church. From its Foundations to the End of the Fith Century [versión inglesa del francés original], 3 vols. 1909-1924, red. 1957-1960.

${ }^{43}$ Tejada Y Ramiro, Juan, cit. (n. 42), p. 44. Es cierto que en el Concilio de Gangres se rechaza plenamente esta posibilidad: "si qua mulier virum proprium relinquens, decedere voluerit nuptias execrans, anathema sit”. Cfr. Concilium Gangrense, can. 14, en LABBE 2, col. 422, pero la problemática en torno a la datación hace que sea dificil utilizarlo para aclarar el sentido del canon que estudiamos. Sozomeno lo coloca antes de un concilio celebrado en Antioquía en el 341; mientras que Sócrates Escolástico después del Concilio de Constantinopla del 360. La doctrina, a su vez, tampoco es unánime: Hefele prefiere la segunda, Laniado el 343 y Barnes, el último en estudiarlo en profundidad, propone el 355. Cfr. Von Hefele, Karl Joseph, Concile de Gangres, en Histoire des Conciles I, pars secunda (Pariis, 1907), pp. 1029-1041; Laniado, Avshalom, Note sur la datation conservée en syriaque du Concile de Gangres, en Pontificium institutum orientalium studiorum, 61/1 (1995), pp. 195-199; BARNES, Timothy, The date of the council of Gangra, en Journal of Theological Studies, 40 (1989), pp. 121-124. Además, el hecho de realizarse en Paflagonia pone aún más de manifiesto la división existente entre el parecer conciliar de oriente y occidente o, al menos, en la zona de las Galias.

${ }^{44}$ Optatus Milevitanus Ep., De schismate Donatistarum, I, 24, en Migne, Patrologia Latina 11, col. 932A-933A. 
carta que dirige a Cresto, obispo de Siracusa ${ }^{45}$ : ya que los donatistas no pensaban aceptar la sentencia del juicio romano por voluntaria assensione, plantea una nueva reunión que sea casi universal, a la que el papa enviará sus legados ${ }^{46}$. El Concilio de Arlés comparte con el de Nicea circunstancias, convocatoria y problemática en relación a los lapsi. No sería de extrañar, por tanto, que, en lo referente a cuestiones relativas al matrimonio, también compartiera postura.

Pues bien, el citado can. 10 concedía la posibilidad de nuevas nupcias en caso de que el marido inocente fuese joven. Esta actitud de comprensión se justifica en la necesidad de evitar que los impulsos los pudieran llevar a pecar, aunque debería recomendárseles que, si era posible, no lo hicieran: "de his qui conjuges suas in adulterio depraehendunt, et idem sunt adulescentes fideles et prohibentur nubere, placuit ut, quantum possit, consilium eis detur ne alias uxores viventibus uxoribus suis, licet adulteris, accipiant" ${ }^{47}$.

Dado lo sorprendente del canon, se ha pretendido hacer una reconstrucción del texto (añadiendo partículas al mismo, o incluso planteando que, en realidad, los santos padres podrían haber recibido una versión contaminada del famoso pasaje de Mateo $)^{48}$. Últimamente se ha especificado que el sentido del canon no es fijar un principio doctrinal ni disciplinario, sino simplemente dar un consejo pastoral pretendiendo que, pese a llevar una vida fuera del consejo, eviten una vida entregada por completo al pecado ${ }^{49}$. Pero lo cierto es que, para evitar la penitencia canónica (y la expulsión definitiva en caso de recaer), no se le aleja de la comunión eclesial. Debemos tener en cuenta que no es un simple concilio local de escasa repercusión, sino uno que algunos han considerado el primer concilio ecuménico, y que compartirá circunstancias, convocatoria y doctrina con el de Nicea. Que se trate de un consejo pastoral no tendría sentido, dado el contexto en el que se convocó .

Sin embargo, el texto más esclarecedor en cuanto a la interpretación canónica del término es, sin duda, el del can. 19 del Concilio de Ancira del año 314, dada la cercanía tanto geográfica y cultural entre la ciudad y Nicea (menos de 300 kilómetros) como la escasa separación temporal de ambas reuniones eclesiales. Además, el carácter disciplinar del Concilio, que regula fundamentalmente as-

45 “[...] prolatae jam sententiae acquiescere nolentes, asserentesque paucos admodum episcopos sententiam tulisse [...] Idcirco mihi sedulo providendum fuit, ut haec quae post depromptum judicium voluntaria assensione jam finita esse debuerant, nunc tandem multorum interventu finem possint accipere [...]”. Cfr. Eusebius Cæsariensis EP., Historia Ecclesiastica, X, 5, Epistola Costanini imperatoris Chresto Syracusorum, en Migne, Patrologia Graeca 20, col. 890A-B.

${ }^{46}$ Dos presbíteros y dos diáconos: "Claudianus et Vuitus presbyteri, Eugenius et Cyriacus diacones, ex urbe Roma missi a Silvestro episcopo", Concilium Arelatense I, Nomina episcoporum cum clericis suis quinam ex quibus provinciis ad Arelatensem synodum convenerint, en MANsI, Sacrorum 2, [rist.] (Graz, 1960), col. 476B.

${ }^{47}$ Concilium Arelatense I (a. 314), en Mansi, Sacrorum 2, [rist.] (Graz, 1960), col. 472. Independientemente de los problemas textuales, pudiendo intercalarse o no el non delante de probentur, lo cierto es que el sentido del canon es el mismo. Cfr. Pelland, Gilles, cit. (n. 7) pp. 133 ss.

${ }^{48}$ Ibíd.

${ }^{49}$ Es la explicación que dan Pelland y Couzel, y qué comparten, entre otros, con San Agustín. 
pectos penitenciales y matrimoniales, da áun mayor fiabilidad al posible empleo como clave de lectura del canon niceano. El texto del canon de Ancira reza así: "Quotquot virginitatem pollicitam prevaricati sunt, professione, inter digamos, id est, qui ad secundas nuptias transierunt, haberi debebunt"50.

El canon trata a quienes rompieron su promesa de virginidad (realizada al Esposo Celeste y, por tanto, con un carácter nupcial indiscutible) del mismo modo que a los bigamos. Poco sentido tendría entonces calificar aquí a éstos como viudos, pues no es posible que el Esposo pueda morir, sino que la lectura más lógica sería considerarlas de la misma manera que se toma a quienes se unieron por segunda vez -como el propio canon lo explica ("qui ad secundas nuptias transierunt")- mientras el primer vínculo aún existía.

Vista la utilización canónica del término, y dado que la literatura conciliar inmediatamente anterior (y relacionada directamente con la problemática rigorista) no expulsa de la comunión eclesial a la viuda, y en ocasiones sí permite segundas

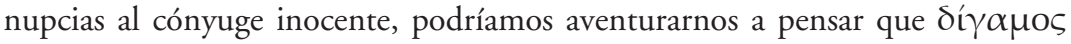
parece referirse a todos aquellos cuyas uniones pudieran ser consideradas adúlteras, ya fuera por volverse a casar (con el anterior cónyuge vivo) como a los viudos.

En cualquier caso, lo que queda de manifiesto es lo discutido del término ${ }^{51}$ : si $\delta$ i $\alpha \mu \rho \varsigma$ se aplica al vuelto a casar por segunda vez, en caso de viudedad o adulterio, la riqueza semántica del término no permite utilizarlo con un solo significado sino con el que cada momento le atribuyó. Además, como hemos visto, la viudedad es también considerada adulterio en algunos momentos por parte de determinadas voces eclesiásticas, con lo que no podemos concluir nada con absoluta certeza. No debemos olvidar que la Iglesia oriental ha conservado la práctica de permitir en determinadas ocasiones nuevas nupcias basándose en la interpretación posible que se puede hacer tanto del texto de Mateo como del canon conciliar ${ }^{52}$. Cierto es también que influirá la legislación imperial, pero no es menos cierto que los cánones de este concilio fueron declarados vigentes por el emperador que lo convocó.

\section{Los $\delta i \gamma \alpha \mu \rho \varsigma$ en la literatura conciliar de la época}

Pero la doctrina de los grandes Concilios Ecuménicos debe ser leída a la luz de los concilios locales, que nos permitirán ver de qué modo se trató a aquellos que se encuentren en situación irregular ${ }^{53}$. Así, el can. 8 del citado concilio de Elvira habla de excomunión a mujeres divorciadas sin causa y unidas a otros: "Item feminae,

\footnotetext{
${ }^{50}$ Concilium Ancyranum, en MANsI, Sacrorum 2, [rist.] (Graz, 1960), col. 533.

${ }^{51}$ Como refleja la existencia de dos escuelas enfrentadas, la de citados Cereti, cit. (n. 9) y Crouzel y Nautin, cit. (n. 10).

${ }^{52}$ GLINKA, Luis, Indisolubilidad y divorcio en las Iglesias Ortodoxas: una contribución al diálogo ecuménico en Teologia: revista de la Facultad de Teología de la Pontificia Universidad Católica Argentina, 51 (1988), p. 61.

${ }^{53}$ Cfr. Rodríguez Díez, José, Indisolubilidad y divorcio del matrimonio cristiano y canónico: ¿indisolubilidad extrinseca relativa de futuro?, en Anuario Jurídico y Económico Escurialense, 39 (2006), pp. 171-214.
} 
quae nulla praecedente causa reliquerint viros suos et alteris se copulaverint, nec in finem accipiant communionem "54.

Sin embargo, el término empleado (copulaverint) no es baladí: se referirá a la unión carnal (copula) ${ }^{55}$ y no al matrimonio (ducere $)^{56}$ cuando no exista una causa, esto es, cuando no se sea víctima (nulla praecedente causa), lo que podría ser interpretado como el permiso dado a la que sí sea inocente. En el canon siguiente, que hemos apenas visto, si emplea el término ducere.

El can. 10, al referirse a las mujeres de catecúmenos abandonadas, vuelve a tratar de modo distinto a quienes conscientemente contraen matrimonio con un adúltero de quienes ignoraban esa situación: "Si ea quam catechumenus relinquit duxerit maritum, potest ad fontem lavacri admitir; hoc et crica foeminas catechumenas erit observandum. Quod si fuerit fidelis quae ducitur ab eo qui uxorem inculpatam relinquit, et quum scierit illum habere uxorem, quam sine causa reliquit, placuit in finem hujusmodi dari communionem" 57 .

Este nuevo tipo de unión dejaría a los nuevos cónyuges en una situación similar (dentro de la comunidad) a la de la contraída entre parte cristiana y no cristiana: en un primer momento, para poder contraer matrimonio válido se exigía la conversión, llegando a disciplinar la separación de la comunión durante algún tiempo de las mujeres que contraían estos matrimonios (can 11, Concilio de Arlés) ${ }^{58}$. Sin embargo, en el territorio africano, dada la enorme cantidad de gentiles primero, y de provenientes de diversas herejías después, el Concilio III de Cartago sólo prohibió tales uniones si eran hijos de obispos o presbíteros (can. 12) ${ }^{59}$, determinación retomada en Calcedonia (can. 14) ${ }^{60}$. A su vez, no mucho tiempo después, los emperadores Valentiniano y Valente prohibieron el

${ }^{54}$ Cfr. Concilios visigóticos e hispano-romanos, Vives, José, Marín Martínez, Tomás y Martínez Díez, Gonzalo (eds.) (Barcelona-Madrid, 1963), pp. 19-33. A su vez, Concilium Eliberitanum, a. 305?, en MANsI, Sacrorum 2, [rist.] (Graz, 1960), col. 7.

${ }^{55}$ Copula, en Lexicon totius latinitatis ab Aegidio Forcellini lucubratum (Padova, 1965), II, p. 864: "Ratione habiti, etymi copula est a cum et apere, et significat vinculum, nexum quo plura simul ligantur et connectuntur. Improprie dicitur de morali quocumque vinculo". El Código Teodosiano lo considera requisito básico para el matrimonio: "ubi copula est ipsum matrimonium". Cfr. Codex Theodosianus, 3,16,2.

${ }^{56}$ Duco, en Lexicon totius latinitatis ab Aegidio Forcellini lucubratum (Padova, 1965), II, pp. 204-206: "speciatim refertur ad nuptias: Vir dicitur ducere aliquam domum, uxorem, vel in matrimonium”. Así lo usa, por ejemplo, Cicerón: "[...] duxit uxorem optimi viri filiam Scipionis” (Cicero, Pro Sexto, 3, 6).

${ }^{57}$ Concilium Eliberitanum, a. 305?, en MANSI, Sacrorum 2, [rist.] (Graz, 1960), col. 7.

58 "De puellis fidelibus quae gentilibus junguntur, placuit ut aliquanto tempore a communione separentur", Concilium arelatense I, can. 11, en MANSI, Sacrorum 2, [rist.] (Graz, 1960), col. $472 \mathrm{D}$.

59 "Item placuit, ut filii vel filiae episcoporum, vel quorumlibet clericorum, gentibus, vel haereticis aut schismaticis matrimonio non jungantur", Concilium Carthaginense III, can. 12, en MANSI, Sacrorum 3, [rist.] (Graz, 1960), col. 882.

60 "Quoniam in quibusdam provinciis concessum est lectoribus et psalmistis uxores ducere, statuit sancta synodus, non licere cuiquam ex his accipere sectae alterius uxorem [...]". Concilium Chalcedonense, can. 14, Acta conciliorum et epistolae decretales, ac constitutiones summorum pontificum, Cossart, Gabriel et al. (a cura di), (Parisiis, 1714), II, p. 607. 
matrimonio de cualquier gentil o extranjero con mujeres provinciales ${ }^{61}$. Si bien el matrimonio entre parte cristiana y no cristiana fue prohibido perpetuamente en diferentes ocasiones (el citado canon de Arlés, el $10^{62}$ y el $31^{63}$ de Laodicea, el 14 del III de Toledo ${ }^{64}$, el 19 del II de Orleans ${ }^{65}$ y el $24^{66}$ del IV de Orleans), en todos ellos queda claro que el matrimonio es ilícito e injusto, pero seguía siendo válido, acaso en la línea de la clásica actitud del África donatista a la que antes nos referíamos (por el contexto socio-religioso del momento), que llevó incluso a prohibir el bautismo de aquellos que, antes de la conversión, habían repudiado a sus esposas, pues la conversión no disolvía los vínculos matrimoniales ${ }^{67}$.

El can. $72^{68}$ del trullano daba la posibilidad de que continuase la cohabitación de un matrimonio de infieles cuando se produce la conversión de uno de ellos, si ambos desean continuar con la unión, y el can. 16 de Elvira ${ }^{69}$, al referirse a la prohibición de matrimonios no ya con infieles sino con herejes, judíos o cismáticos, castigará a los padres que entreguen a sus hijas a tales matrimonios. El citado canon trullano declaraba írritos los matrimonios entre infieles y católicos, pero

${ }^{61}$ I. unic. De nuptiis gentil. C. Theod. lo que ya se relaciona directamente con las antiguas leyes romanas que buscaban garantizar la pureza de sangre (Ulpiano, fragment., tit. 3, can. 5; Caio, Instit. Tit. 4). Nótese, sin embargo, que, aunque se pueda interpretar de otro modo, la norma no atañe directamente a cristianos sino a romanos, poseedores del ius connubii.

${ }^{62}$ "Non oportere eos qui sunt ecclesiae indiscriminatim suos filios haereticis matrimonio conjungere", Concilium Laodicenum, sub Silvestro, can. 10, en Mansi, Sacrorum 2, [rist.] (Graz, 1960), col. 565.

${ }_{63}$ "Quod non oportet cum omni haeretico matrimonium contrahere, vel dare filios aut filias: sed magis accipre, si se Christianos futuros profiteantur", Concilium Laodicenum, sub Silvestro, can. 21, en Mansi, Sacrorum, 2, [rist.] (Graz, 1960), col. 569.

${ }^{64}$ "Suggerente concilio, id gloriosissimus dominus noster canonibus inferendum praecipit, ut Judaeis non liceat Christianas habere uxores vel concubinas [...]", Concilium toletanum III, can. XIV, en Mansi Sacrorum 9, [rist.] (Graz, 1960), col. 996.

65 "Placuit ut nullus Christianus Judaeam, neque Judaeus Christianam in matrimonio ducat uxorem, quia inter hujusmodi personas illicita nuptias esse censemus. Qui si comminiti a consortio hoc se separare distulerint, a communionis gratia sunt sine dubio submovendi", Concilium Aurelianense II, can. XIX, en Mansi, Sacrorum 8, [rist.] (Graz, 1960), col. 838.

${ }_{66}$ "Quaecumque manciapia sub specie conjugii ad ecclesiae septa confugerint, ut per hoc credant posse fieri conjugium, minim eis licentia tribuatur, nec talis conjunctio a clericis defensetur: quia probatum est, ut sine legitima traditione conjuncti, pro religione ordine, statuto tempore ab ecclesiae comminione suspendatur ne in sacris loci turpi concubitu misceantur", Concilium Aurelianense IV, can. 24, en in Mansi, Sacrorum 9, [rist.] (Graz, 1960), col. 117.

${ }^{67}$ Tejada Y Ramiro, Juan, cit. (n. 42), p. 45.

68 "Non licere virum orthodoxum cum muliere haeretica conjugi, neque vero orthodoxam cum viro haeretico copulari [...] Si autem aliqui qui adhuc sunt infideles, et in orthodoxorum gregem nondum relati sunt, sunt inter se legitimo matrimono conjuncti: deinde hic quidem eo quod est honestum electo, ad lucem veritatis accurrerit... fideli vero homini placeat cum infideli cohabitare, vel e contra, se invicem separentur [...]". Concilium in Trullo Palatii Imperatorii, can. LXXII, en Acta conciliorum et epistolae decretales, ac constitutiones summorum pontificum, COSSART, G. et al. (a cura di), (Parisiis, 1714), III, p. 1687.

${ }_{69}$ "Haeretici si se transferre noluerint ad ecclesiam catholicam, nec ipsis catholicas dandas esse puellas. Sed neque Judaeis, neque haeretici, dare placuit [...] Si contra interdictum fecerint parentes, abstineri per quinquennium placet", Concilium Eliberitanum, a. 305?, en MANSI, Sacrorum 2, [rist.] (Graz, 1960), col. 8. 
la situación de los herejes era distinta ${ }^{70}$. El matrimonio era válido y, de hecho, la solución que dan los Padres Conciliares a estos matrimonios es la separación, entendida más como una disolución efectiva del matrimonio que como una interrupción de la cohabitación ${ }^{71}$, declarando nulo desde el principio el matrimonio. Esta evolución, que concluye con la enunciación del impedimento de disparidad de cultos, sería similar a la que tendría el caso del segundo matrimonio, que en este caso concluiría como impedimento por ligamen.

Debemos también notar que nos referimos a uniones de algún modo voluntarias y que tienen vocación de estabilidad, distintas de las simplemente adúlteras, más relacionadas con los desórdenes de tipo sexual, que fueron castigadas con dureza, especialmente si afectaban a quienes pertenecían a un estado de vida especial, tales como viudas o vírgenes. Así sucede con can. 47 de Elvira, en el que se prescribe que al que cometiere adulterio muchas veces sólo se le acepte en la comunidad in fine mortis, pero se le dé la comunión si prometiera la enmienda (si se promiserit cessaturum $)^{72}$. Este tratamiento de benignidad, sin embargo, no quita que se busque evitar el indiferentismo, y en caso de reincidencia, se le prive totalmente de ella ${ }^{73}$. Con la misma pena se castiga a la adúltera que concibiera en ausencia del marido y matara a la criatura (can. 63) ${ }^{74}$. Si, por el contrario, sólo adulterase una vez, la penitencia era de 5 años, a no ser que alguna circunstancia obligase a adelantar la readmisión (can. 69) ${ }^{75}$. También se perseguirá a quienes dieran licencia a sus mujeres para adulterar, fueran clérigos (can. 65) ${ }^{76}$ o laicos (can. 70) $)^{77}$.

Este desorden puede relacionarse con otros que contemplan los padres conciliares y que, si bien no se refieren expresamente al concubinato, no excluyen esta posibilidad. Se privaba de la eucaristía durante un año a la joven que contraía matrimonio con el hombre con quien mantuvo relaciones antes de casarse (can. $14)^{78}$, lo que demuestra la escasa consideración que se le daba al delito, pues no

${ }^{70}$ San Is idoro de Sevilla, De haeresi et schismate, Etimologías VI, 19, 51. (a cura di), Oroz Reta, José y Marcos Casquero, Manuel Antonio (Madrid, 1993), p. 688.

${ }^{71}$ Prueba de ello es la Ley 15 , tit. $2^{\circ}$, part. IV, que reza: “desvaramiento de la ley es la sexta cosa que embarga el casamiento. Ca ningún christiano debe casar con judia, nin con Mora, nin con Hereja, non con otra mujer que no toviesse la ley de christianos, et si cassase, non valdrie el casamiento".

72 "Si quia fidelis habens uxorem, non semel, sed saepe moechatus, in fine mortis est conveniendus. Quod si se promiserit cessaturum, detur ei communion [...]”, Concilium Eliberitanum, a. 305?, en Mansi, Sacrorum 2, [rist.] (Graz, 1960), col. 13.

${ }^{73}$ Esta persecución del indiferentismo no es extraña, se verá, por ejemplo, en el Concilio de Angers: "hi quoque qui alienis uxoribus, superstitibus ipsorum maritis nomine conjugii abutuntur, a communione habeantur extranei". Cfr. Concilium Andegavense, can. 6, en LABBE IV, col. 1021.

74 "Si qua mujer per adulterium, absente marito, concepit, idque post facinus occiderit, placuit neque in finem dandam esse communionem, eo quod germinaverit scelus", Concilium Eliberitanum, a. 305?, en Mansi, Sacrorum 2, [rist.] (Graz, 1960), col. 16.

75 "Si quis forte habens uxorem fuerit lapsus, placuit eum quinquennium agere de ea re poenitentiam, et sic reconciliari; nisi necessitas infirmitatis cogerit ante tempus dare communionem. Hoc et circa foeminas observandus", Concilium Eliberitanum, a. 305?, en MansI, Sacrorum 2, [rist.] (Graz, 1960), col. 17.

${ }^{76}$ Ibíd., p. 16.

${ }^{77}$ Ibíd., p. 17.

${ }^{78}$ Ibíd., p. 8. 
se exigía penitencia pública ("post annum sine poenitentia"). Si el matrimonio no venía a subsanar la situación, o no había sido relaciones prematrimoniales sino una vida licenciosa ("vel si alios cognoverint viros") la penitencia aumentaba a cinco años. La misma penitencia preveía el citado can. 72 para la viuda que había tenido relaciones con un hombre después de su viudez, si regularizaba su situación casándose con él. Pero si se casaba con otro, se cerraba las puertas a todo perdón humano y el cónyuge se veía excomulgado por diez años, no pudiendo remitírsele la pena ni aún en artículo de muerte: "Si qua vidua fuerit moechata et eundem postea habuerit maritum, post quinquennii tempus acta legitima poenitentia placuit eam communionem reconciliari. Si alium duxerit relicto illo, nec in fine dandam ei esse communionem, vel si fuerit ille fidelis, quem accepit, communionem non accipiat, nisi post decem annos acta legitima poenitentia, nisi infirmitas coegerit, velocius dare communionem" $"$.

Vemos nuevamente que, pese a la dureza con la que trata a la viuda deshonesta (propio del carácter del concilio), el nuevo cónyuge sí puede comulgar, con lo que se observa un trato distintivo a uno y a otro en función de la vida pasada de cada uno. Además, debemos distinguir entre la obligación de la penitencia pública y la recepción de la comunión a la que antes nos referíamos.

Al mismo tiempo, la actitud de atención y vigilancia sobre todo ante los que pueden sucumbir más fácilmente en el pecado, está presente en otros momentos. Se ve, por ejemplo, también en tierra gala, además del citado can. 10 de Arlés, como se evitaba aplicar penitencias públicas que, como sabemos, sólo podía aplicarse una vez. Esto se tuvo en cuenta cuando Avito de Vienne juzgue a un tal Vincomal, que tenía grandes problemas para mantenerse fiel a su mujer ${ }^{80}$ : "la jerarquía eclesiástica, por su parte, hizo frecuentemente suya esta actitud prudente ante el recurso a la penitencia canónica. En este sentido, los estudios que Cyrille Vogel dedicó a la disciplina penitencial en las iglesias galas de época antigua y alto medieval advierten al historiador de la necesidad de contemplar las penas de excomunión decretadas en las resoluciones conciliares y la penitencia canónica como dos realidades distintas: en la mayoría de supuestos, el pecador excomulgado no se veía obligado a asumir la penitencia canónica para ser restablecido en la comunión" 81 .

Esta actitud de comprensión de la realidad, esto es, aceptar la inestabilidad

\footnotetext{
${ }^{79}$ Concilium Eliberitanum, a. 305?, en Mansi, Sacrorum 2, [rist.] (Graz, 1960), p. 17.

${ }^{80}$ WooD, Ian, Letters and Letter-Collections from Antiquity to the Early Middle Ages: The Prose Works of Avitus of Vienne, en The Culture of Christendom (London, 1993), pp. 29-43; SHANZER, Danuta y Wood, Ian, Avitus of Vienne: Selected Letters and Prose Translated Text for Historians 38 (Liverpool, 2002), pp. 285-286; Vilella, Josep, El canon 3 del Concilio de Orange (441), el Ad Ecclesiam de Salviano de Marsella y los debates en torno a la penitencia in extremis en la Galia de mediados del siglo V, en Revue d'etudes augustiniennes et patrsitiques, 58 (2012) pp. 287-319.

${ }^{81}$ Vilella, Josep, El canon 3 del Concilio de Orange (441), el Ad Ecclesiam de Salviano de Marsella y los debates en torno a la penitencia in extremis en la Galia de mediados del siglo $V$, en Revue d'etudes augustiniennes et patristiques, 58 (2012) pp. 287-319: "Avito optó por esta línea contemporizadora tras percibir en Vincomal cierta proclividad a los pecados de la carne (iunenis uitiis, senex annis), que amenazaban con condenar definitivamente a su alma si se le obligaba a someterse a la no reiterable penitencia canónica (Epist. 18, p. 49, 1, 28)".
} 
del alma, no es algo extraordinario en el caso de Avito juzgando a Vincomal: en el Concilio de Agde (506) se puso de manifiesto la necesidad de conceder con prudencia la penitencia canónica a los jóvenes, aceptándose sólo cuando se haya perdido toda definitivamente toda peccandi occasio ${ }^{82}$.

De aquí la tolerancia que había mostrado incluso San Agustín cuando se refiere al concubinato ${ }^{83}$ : "[...] De concubina quoque, si professa fuerit nullum se alium cognituram, etiamsi ab illo cui subdita est dimittatur, merito dubitatur utrum ad percipiendum Baptismum non debeat admitti. Quisquis etiam uxorem in adulterio deprehensam dimiserit, et aliam duxerit, non videtur aequandus eis qui excepta causa adulterii dimittunt et ducunt: et in ipsis divinis sententiis ita obscurum est utrum et iste, cui quidem sine dubio adulteram licet dimittere, adulter tamen habeatur si alteram duxerit, ut, quantum existimo, venialiter ibi quisque fallatur. Quamobrem quae manifesta sunt impudicitiae crimina, omni modo a Baplismo prohibehda sunt, nisi mutaticne voluntatis et poenitentia corrigantur; quae autem dubia, omni modo conandum est ne fiant tales conjunctiones. Quid enim opus est in tantum discrimen ambiguitatis caput mittere? Si autem factae fuerint, nescio utrum ii qui fecerint, similiter ad Baptismum non debere videantur admitti" ${ }^{4}$.

${ }^{82}$ Cfr. Ibíd.: Conc. Agath. (506), can. 15, Munier, Charles (a cura di), Corpus Christianorum, Serie Latina 148 (Turnhout, 1963), pp. 192-228, esp. p. 201: “iuuenibus etiam paenitentia non facile committenda est propter aetatis fragilitatem"; cfr. en este mismo sentido Conc. Avrel. (538), can. 27, en DE ClerCQ, Carles (a cura di) Corpus Christianorum, Serie Latina 148A (Turnhout, 1963), pp. 114-130, esp. p. 124: “de paenetentum conuersione. Vt ne quis benedictionem paenetentiae iunenibus persunis credere praesumat; certe coniugatis nisi ex consensu parcium et aetate iam plena eam dare non audeat".

${ }^{83}$ De bono conjugali, C5, 5: "Solet etiam quaeri, cum masculus et femina, nec ille maritus nec illa uxor alterius, sibimet non filiorum procreandorum, sed propter incontinentiam solius concubitus causa copulantur ea fide media, ut nec ille cum altera nec illa cum altero id faciat, utrum nuptiae sint vocandae. Et potest quidem fortasse non absurde hoc appellari connubium, si usque ad mortem alteriuse eorum id inter eos placuerit et prolis generationem, quamvis non ea causa coniuncti sint, non tamen vitaverint, ut vel nolint sibi nasci filios, vel etiam opere aliquo malo agant, ne nascantur. Ceterum si vel utrumque vel unum horum desit, non invenio, quemadmodum has nuptias appellare possimus. Etenim si aliquam sibivir ad tempus adhibuerit, donec aliam dignam vel honoribus vel facultatibus suis inveniat, quam comparem ducat, ipso animo adulter est, nec cum illa, quam cupit invenire, sed cum ista, cum qua sic cubat, ut cum ea non habeat maritale consortium. Unde et ipsa hoc sciens ac volens impudice utique miscetur ei, cumquo non habet foedus uxorium. Verumtamen si ei tori fidem servet et, cum ille uxorem duxerit, nubere ipsa non cogitet atque a tali prorsus opere continere se praeparet, adulteram quidem fortassis facile appellare non audeam; non peccare tamen quis dixerit, cum eam viro, cuius uxor non est, misceri sciat? Iam vero si ex illo concubitu, quantum ad ipsam attinet, nonnisi filios velit et, quidquid ultra causam procreandi patitur, invita patiatur, multis quidem ista matronis anteponenda est, quae tametsi non sunt adulterae, viros tamen suos plerumque etiam continere cupientes ad reddendum carnale debitum cogunt non desiderio prolis, sed ardore concupiscentiae ipso suo iure intemperanter utentes, in quarum tamen nuptiis bonum est hoc ipsum, quod nuptae sunt. Ad hoc enim nuptae sunt, ut illa concupiscentia redacta ad legitimum vinculum non deformis et dissoluta fluitaret, habens de se ipsa irrefrenabilem carnis infirmitatem, de nuptiis autem indissolubilem fidei societatem, de se ipsa progressum immoderate coeundi, de nuptiis modum caste procreandi. Etsi enim turpe est libidinose uti vellef marito, honestum est tamen nolle misceri nisi marito et non parere nisi de marito".

${ }^{84}$ S. Aureli Augustini hipponensis eP., De fide et operibus, I, can. XIX, n. 34, en Migne, Patrologia Latina 40, col. 221. 
El Concilio de Toledo del año 400 se mantiene en la misma posición. No permite comulgar al casado que mantiene una concubina, pues debe haber un solo vínculo: "Si quis habens uxorem fidelem, si concubinam habeat, non communicet. Ceterum qui non habet uxorem, \& pro uxore concubinam habet, a communione non repellatur, tantum ut unius mulieris, aut uxoris, aut concubinae (ut ei placuerit) sit conjunctione contentus; alias vero vivens abjiciatur, donec desinat, \& per poenitentiam revertatur" 85 .

La orientación dada por el Concilio de Toledo se mantuvo durante años. Así, San Isidoro de Sevilla escribía: "Christiano non dicam plurimas, sed nec duas, simul habere licitum est, nisi unam tantum aut uxorem aut certe loco uxoris concubinam" $"$, pasaje que, junto con las disposiciones del Concilio de Toledo, fue incluido en el decreto de Graciano, que definía además quién tiene la calidad de concubina: "Concubina autem hic ea intelligitur, quae cessantibus legalibus instrumentis unita est, et eoniugali affectu ascistur; hanc coniugem facit affectus, concubinam vero lex nominat" ${ }^{\prime 7}$. Esta expresión podría servir para ilustrar el espíritu con el que la Iglesia leía la situación: acaso la ley, o las circunstancias sociales y económicas, no permiten que ocupe en la sociedad el lugar que ya ocupaba en el ánimo del esposo.

En caso de que se hubiera formalizado la unión, también existen intentos de comprensión de la situación para, sobre todo, y volvemos otra vez a lo mismo, tratar de evitar el pecado de la parte inocente. Tal es el caso del concilio de Vannes, en el año 461 que, en su can. 2, señalaba que era lícita la nueva unión si el adulterio del cónyuge se había comprobado ("Eos quoque, qui relicti uxoribus suis, sicut in evangelio dicitur, excepta causa fornicationis, sine adulterii probatione alias duxerint, statuimus a communione similiter arcendos: ne per indulgentiam nostram praetermissa peccata alios ad licentiam erroris invitent") ${ }^{88}$, del mismo modo que algunos años después lo hizo el propio concilio de Agde (506) en el can. 15: "Poenitentes, tempore quo poenitentiam petunt, impositionem manuum \& cilicium super caput a sacerdote, sicut ubique constitutum est, consequantur. Si autem comas non deposuerint, aut vestimenta non mutaverint, abjiciantur; et nisi digne poenituerint, non recipiantur. Juvenibus etiam poenitentia non facile committenda est ptopter aetatis fragilitatem. Viaticum tamen omnibus in morte positis non negandum" 89 .

Este tipo de cánones, lejos de ser considerados como divorcistas, nos tienen que hacer ver la actitud de comprensión que manifiestan en determinadas ocasiones los padres conciliares, conscientes de las circunstancias sociales que rodean

${ }^{85}$ Concilium toletanum I (a. 400), can. 17, en Mansi, Sacrorum 3, [rist.] (Graz, 1960), col. 1001B-C.

${ }^{86}$ IsIDORus, De distantia Novi et Veteris Testamenti, Dist. XXXIV, cap. 5; AlPhOnSI TostatI, Hispani Episcopi Abulensis, Philosophi, Theologi, Ac Pontificii Juris, Caesareique Consultissimi, Necnon Lingua: Graecae, \& Hebraicas Peritissimi, Commentaria in Primam Partem, I. Regum (Venetiis, MDCCXXVIII), XI, cap. VIII, q. CCIX, p. 238.

${ }^{87}$ Decretum Gratiani, II, Distintio XXXIV, can. 3 Pallea, en Migne, Patrologia Latina 187, 0188A: "Concubina autem hic ea intelligitur, quae cessantibus legalibus instrumentis unita est, et coniugali affectu adscitur; hanc coniugem facit affectus, concubinam vero lex nominat. De hac dicitur in concilio Toletano I, can. 17".

${ }^{88}$ Concilium Veneticum, can. 2, en MANSI, Sacrorum 7, [rist.] (Graz, 1960), col. 953C.

${ }^{89}$ Concilium Agathense (a. 506), en Mansi, Sacrorum 8, [rist.] (Graz, 1960), col. 327B-C. 
estos casos. El concepto de nulidad matrimonial se está todavía desarrollando, y la Iglesia responde a los casos que se le presentan aplicando principios de justicia y misericordia ${ }^{90}$.

\section{La EXCEPCiONeS CANÓNICAS DE LA ÉPOCA POSTERIOR (Siglos VI-IX)}

\section{Los Concilios locales}

Si bien la actitud general de la época es contraria a estas situaciones, y a aceptar nuevas uniones, lo que sí es cierto es que, como hemos visto, el recurso a la penitencia canónica, que exigía una dura y humillante conversión, y que además, en caso de recaer, les cerraba definitivamente las puertas de la Iglesia (lo que, de haber formado nuevas familias, no sería extraño que cayesen), fue paulatinamente mitigada por algunos concilios posteriores, desarrollando para ello un elenco de causas por las que se permitían nuevas uniones. No podemos (ni debemos) hablar de causas de divorcio, pero sí de situaciones que debían de ser habituales, y de ahí que requieran una respuesta concreta de la autoridad para garantizar la paz (social y espiritual) de la comunidad.

El III Concilio de Orleáns, en el can. 24, seguía en la misma línea antes mencionada: "Ut ne quis benedictionem poenitentiae juvenibus personis credere praesumat: certe conjugatis, nisi ex consensu partium \& aetate jam plena, eam dare non audeat" ${ }^{11}$.

Teodoro de Canterbury ${ }^{92}$ reflejará esto en el can. 10 del Concilio de Hereford del 673: "Pro conjugiis, ut nulli liceat nisi legitimum habere connubium. Nulla incestum faciat, nullus conjugem propriam, nisi ut Sanctum evangelium docet, fornicationis causa, relinquat. Quod si quisquam propriam expulerit conjugem legitimo sibi matrimonio conjunctam, si Christianus recte esse voluerit, nulli alteri copuletur; sed ita permaneat, aut propriae reconcilietur conjugi"93.

Algunos de estos cánones pasaron a otras obras, como el Iudicium Clementis, atribuido a Willibrord que, por ejemplo, en el caso de cautiverio de uno de los cónyuges, decía: Si cuius uxorem ostes rapuerint et non potuerint eripere eam, post annum integrum licet ei aliam ducere, et si potea redierit, licet eam alio viro ducere $(\text { can. 19) })^{94}$.

\footnotetext{
${ }^{90}$ Recuérdese la actitud que recomienda S. Cirilo de Alejandría, que en el Oriente cristiano evolucionó en la defensa del matrimonio monogámico, según el mandato evangélico, pero desde su interpretación de Mt. 19: 9 ha tomado una actitud de misericordia, sirviéndose de la "oiconomia" para conceder el divorcio a aquellos matrimonios destruidos culpablemente o por motivos especiales. Cfr. GLinKA, Luis, Indisolubilidad y divorcio en las Iglesias Ortodoxas, una contribución al diálogo ecuménico, en Teología: Revista de la Facultad de Teología de la Pontificia Universidad Católica Argentina, 51 (1988), pp. 59-70, esp. p. 61; MAI, Angelo, Scriptorum veterum nova collectif (Roma, 1938), pp. 269 ss; MANSI, Sacrorum 2, [rist.] (Graz, 1960), pp. 997-1010.

${ }^{91}$ Concilium Aurelianense III (Tercero en la numeración de Migne) Conc. Di Orléans (a. 538), can. 24, en Mansi, Sacrorum 9, col. 18C.

${ }^{92}$ Cfr. Kelly, William, Pope Gregory II on divorce and remarriage: a canonical-historical investigation of the letter Desiderabilem mihi, with special reference to the response Quod proposuisti (Roma, 1976), p. 98.

${ }^{93}$ Concilium Herufordense (Conc. di Hereford, a. 673), can. 10, en MansI, Sacrorum 11, [rist.] (Graz, 1960), col. 130B-C.

${ }^{94}$ Judicium Clementis, en Councils and Ecclesiastical Documents relating to Great Britain and Ireland, Haddan, Arthur West y StubBs, William, 3, (Oxford 1871), pp. 226-227.
} 
En el Concilio de Verberie, en el $752^{95}$, se hizo una nueva lista de motivos por los cuales se autorizaban nuevas uniones: el incesto del esposo con la propia hija (Si quis filiastrum vel filiastram suam ante episcopum tenuerit ad confirmationem, separetur ab uxore sua, \& numquam aliam accipiat, can. 2) o de la esposa con el hijo o hijastro (Si quis cum matre \& filiam fornicatus est, ignorante matre de filia, \& filia de matre: ille numquam accipit uxorem: illae, vero, si voluerint, accipiant maritos. Si autem hoc scierint ipsae feminae, absque maritis perpetuo maneant, can. 10) y, finalmente, cuando por causa del trabajo el esposo deba trasladar su residencia y, siendo posible, la esposa lo rechace (Si homo fornicatus fuerit cum muliere, \& frater ejus nesciens eadem duxerit uxorem; frater eo quod fratri crimen celaverit, septem annos poeniteat; \& post poenitentiam nubat. Muliere autem usque ad mortem poeniteat, et sine spe conjugii maneat, can. 18$)^{96}$.

En realidad, muchas de estas causas podrían considerarse como motivos de nulidad o incluso semejantes a procesos de muerte presunta, pero eso sería aplicar categorías actuales a situaciones del pasado. Para bien o para mal, y pese a la

95 Concilium Vermeriense (Conc. di Verberie, a. 752), Canones Concilii Vermeriensibus a Gratiano, aliisque adscipti, en MAnsi, Sacrorum 12, [rist.] (Graz, 1960), p. 566B-C y 567A.

${ }^{96}$ Concilium Vermeriense (Conc. di Verberie, a. 752), Canones Concilii Vermeriensibus a Gratiano, aliisque adscipti, en MANsI, Sacrorum 12, [rist.] (Graz, 1960), p. 566B-C y 567A; Concilium Vermeriense (a. 752), Acta Conciliorum et Epistolae decretales, ac Constitutiones Summorum Pontificum, Hardouin, Jean. (ed.), 3, pp. 1989 ss., can. 2: De eo qui cum uxoris suae filia carnale commercium habuit: "Si aliquis cum filiastra sua manet, nec matrem, nec filiam ipsius potest habere; nec ille, nec illa aliis se poterunt conjungere ullo umquam tempore. Attamen uxor ejus, si ita voluerit, si se continere non potest, si posteaquam cognovit quod cum filia sua vir ejus fuit in adulterio, carnale commercium cum eo non habet, nisi voluntate abstinet, potest alio nubere" (p. 1990D); can. 5: De eo cui mortem uxor cum aliis machinata est: "Si qua mulier mortem viri sui cum aliis hominibus consiliavit, \& ipse vir ipsius homine se defendendo occiderit, \& hoc probare potest; ille vir potest ipsam uxorem dimittere, \& si voluerit aliam accipiat.” (p. 1990E); can. 6: De ingenuo qui ancillam duxit pro ingenua, quae servo nupsit pro ingenuo: "Si quis ingenuus homo ancillam uxorem acceperit pro ingenua, si ipsa femina postea fuerit inservita, si redimi non potest, si ita voluerit, liceat ei aliam accipere. Similiter \& mulier ingenua si servum accipiat pro ingenuo, et postea pro qualicumque causa inservitus fuerit, nisi pro inopia fame cogente se vendiderit, \& ipsa hoc consenserit, \& de pretio viri sui a fame liberata fuerit; si voluerit, potest eum dimittere, $\&$, si se continere non potest, alium ducere. Similiter \& de muliere, si se vendiderit, \& vir ejus ita consenserit, taliter potest stare, si se separaverint. Poenitentiam tamen amborum necessaria est. Nam qui de pretio paris sui de talis necessitate liberatus fuerit, in tali conjugio debet permanere, \& non separari" (1990E-1991A); can. 9: De muliere quae virum suum in alio pago sequi non vult: "Si quis necessitate inevitabili cogente in alium ducatum seu provinciam fugerit, aut seniorem suum cui fidem mentiri non poterat, secutus fuerit; \& uxor ejus, cum valet \& potest, amore parentum aut rerum suarum, eum sequi noluerit: ipsa omni tempore, quamdiu vir ejus, quem secuta non fuit, vivit, semper innupta permaneat. Nam ille vir ejus, qui necessitate cogente in alium locum fugit, si se abstinere non potest, aliam uxorem cum poenitentia potest accipere." (p. 1991C); can. 10: De filio qui cum noverca moechatus est: "Si filius cum noverca sua uxore patris sui dormierit, nec ille nec illa possunt ad conjugium pervenire. Sed ille vir, si vult, potest aliam uxorem habere: sed melius est abstinere" (p. 1991D); can. 11: De eo qui cum privigna vel cum uxoris sorore moechatu: "Si quis cum filiastra sua dormierit, simili sententia stare potest: \& cum sorore uxoris suae, simili modo stare potest." (p. 1991D); can. 18: De eo qui cum uxoris suae consobrina moechatur: "Qui cum consobrina uxoris suae manet, sua careat, \& nullam aliam habeat: illa mulier quam habuit, faciat quod vult. Hoc ecclesia non recipit." (p. 1992B). 
tendencia habitual de los concilios de separar de la comunión a los adúlteros, lo cierto es que, en algunos concilios locales, al autorizar nuevas uniones, se estaban también autorizando el acceso a los sacramentos. Lo contrario carecería de sentido.

De hecho, pronto se presentaron causas en las que no es posible la simple equiparación ni a la nulidad ni a la muerte presunta. Una enfermedad sobrevenida era también motivo de la posibilidad de un nuevo matrimonio ${ }^{97}$ : así sucederá en el Concilio de Compiegne, en el 757: "Si vir leprosus mulierem habeat sanam, si vult ei donare commeatum ut accipiat virum, ipsa foemina, si vult, accipiat. Similiter \& vir" (can. 16) ${ }^{98}$. En este caso, no podemos tratar de reconducir la posibilidad de acceso al matrimonio (y, por ende, a la comunión) del nuevo esposo o esposa con una teórica nulidad del matrimonio, pues se supone que cuando contrajeron matrimonio no debía de estar infectada una de las partes y, por tanto, en nada afectaría a la validez de las primeras nupcias. Ya sabemos que la enfermedad de la lepra no azota a la sociedad contemporánea como a las antiguas, pero su ejemplo es muestra del carácter e x c e p c i o n a l de la causa y de la e x c e p c i o n a $\mathrm{l}$ i d a d con que la Iglesia acudía al remedio de quienes se encontraban en una situación harto dramática.

Apenas unos años después, el Concilio Romano del 825 se refería a causas similares ${ }^{99}$, si bien, en realidad, cada vez era más firme la oposición incluso en los pocos concilios en los que ya se discutía el argumento, quedando reducido casi solo a la cuestión de la fornicación, sin quedar si quiera claro que en ese punto se

${ }^{97}$ Lozano, F., Divorcio y nuevo matrimonio (Estella, 1971), p. 148.

98 Concilium Compendiense (Concilio di Compiègne, a. 757), Synopsis Canonum Ecclesiae Latinae: qua Canones Spurii, Epistolae Adulterinae et Decreta Suppositia istius Ecclesiae Conciliorum in Lucem proferuntur, et a Veris ac Genuinis dignoscuntur: quibus accesserunt Annotationibus quaedam Suppletoriae in Synopsin Canonum Ecclesiae Graecae Conciliorum, Nuper editam, Laurence Howell (ed.), (Londini, MDCCX), p. 345: can. 8: "Siqua uxor cum fratre conjugis sui moechatur, frater vel uxor numquam quo vivunt habeant conjugium. Ille autem, cujus uxor fuit, alteram accipiat"; can. 10: "Si pater sponsa filii sui oppresserit, \& postea filius eam acceperit, pater ejus postea non habeat uxorem, \& ipsa foemina non habeat virum, quia non dixit quod pater ejus cum ipsa mansisset: Filius vero ejus qui nesciens fecit, accipiat mulierem legitimam." (p. 345); can. 13: "Siquis conjugem dimiserit, \& monasterium aut velari permiserit, vir illius accipiat aliam mulierem legitimam: Similiter \& mulier faciat." (p. 345); can. 14: "Si quis cum matre \& flia adulterasset, matre nesciente quod cum filia esset, \& filia quod cum matre esset; ille vir, si mulierem acceperit, dimittat; \& usque in diem mortis uxorem ne habeat. Illa autem mater, \& illa filia viros habeant." (p. 345); can. 15: "Qui cum una sorore in adulterio mansit, of alteram in publico accepit usque in diem mortis non habeat mulierem; sed illae duae sorores habeant maritos." (p. 345); Concilium Compendiense, Acta Conciliorum et Epistolae decretales, ac Constitutiones Summorum Pontificum, Hardouin, J. (ed.), 3, coll. 2003 y ss: can. 8, col. 2005C; can. 10, col. 2005D; can. 13, col. 2005E; can. 14, col. 2006A; can. 15, col. 2006A-B; can. 16, col. 2006 B.

99 "Nulli liceat excepta causa fornicationis adhibitam uxorem relinquere, et deinde aliam copulare: alioquin trasgressorem priori convenit sociari conjugio. Sin autem vir et uxor divertere pro sola religiosa inter se consenserint vita, nullatenus sine conscientia episcopi fiat, ut ab eo singulariter praeviso consituantur loco. Nam uxore nolente, aut altero eorum, etiam pro tali re matrimonium non solvatur", Concilium romanum, a. 825, en MANSI, Sacrorum 14, [rist.] (Graz, 1960), col. 1009A. 
autorizasen otras nupcias. Así sucederá en los cann. 41- 46 del concilio de Tibur $(895)^{100}$ o en el can. 16 del Concilio de Bourges ${ }^{101}$.

\section{Los Libros Penitenciales}

Pero, además de los concilios locales y provinciales (por no entrar nuevamente en la discusión en torno al canon 8 de Nicea), los Libros penitenciales también arrojan algunas excepciones a la actitud general ${ }^{102}$. Cuando los religiosos son enviados a las islas británicas para evangelizar aquellas lejanas tierras, surge esta fuente que, junto al derecho secular, de marcado acento germánico, adopta muchos de los principios jurídicos de la época, transfiriéndolos a un contexto cristiano. Así, la idea popular de la justicia en Irlanda durante este período desempeña un papel importante en la formación de una nueva forma canónica, especialmente en la filosofía del castigo que rige las penas prescritas por pecados particulares ${ }^{103}$.

Y esta nueva fuente, como no podía ser de otro modo, también recoge la actitud que hemos rastrado en los textos conciliares. El penitencial de Teodoro ${ }^{104}$, por ejemplo, se dedicó con detalle al asunto de las nuevas nupcias. Si la esposa había sido infiel, el marido podía repudiarla y casarse con otra, si la infiel era su primera esposa. Si hacía penitencia por sus pecados, después de cinco años, también la mujer podía casarse otra vez: "Si cujus uxor fornicata fuerit, licet dimittere eam et aliam accipere; hoc est, si vir dimiserit uxorem suam propter fornicationem, si prima fuerit, licitum est ut aliam accipiat uxorem, ilia vero, si voluerit penitere peccata sua, post $V$. annos alium virum accipiat".

La mujer, sin embargo, no podia repudiar a su marido, aunque fuese adúltero, a menos que pretendiera abrazar la vida monástica: "Mulieri non licet virum dimittere licet sit fornicator, nisi forte pro monasterio. Basilius hoc judicavit".

Los cónyuges podian concederse licencia para entrar en la vida religiosa y

${ }^{100}$ Concilium Triburiense, en LABBE 9, coll. 461-463.

${ }^{101}$ Concilium Bourgensis, can. 16, en LABBE 9, col. 1031: "Ut qui uxorem fornicationis dimiserit, alteram illa vivente non ducat. Ut illi qui uxores legitimas sine culpa fornicationis dimittunt, alias non accipiant illis viventibus, nec uxores viros, sed sibi sibimet reconcilietur".

${ }^{102}$ Vogel, Cyrille, Il peccatore e la penitenza nel Medioevo (Torino, 1988), p. 155.

${ }^{103}$ Cfr. RankIN, Travis, Jurisdiction in the sacrament of penance: a canonical-theological schema (Leuven, 2011), pp. 10-11; BELDA INIESTA, Javier, Excommunicamus et Anathematisamus: predicación, confesión e inquisición como respuesta a la herejía medieval (1184-1233), en Anuario de Derecho Canónico, 2 (2013), p. 120. Nace así un instituto jurídico-sacramental particular, la conmutación, que verá la luz para los casos en que resultaba imposible una penitencia ya fueran por motivos de enfermedad, discapacidad, edad, etc. Se prevé la posibilidad de sustituir con el pago de una cantidad de dinero la satisfacción prevista. Era costumbre del lugar la aceptación de multas monetarias en lugar de sanciones impuestas por las autoridades seculares, y esto fue recibido en algunos de los penitenciales en forma de relajación de la penitencia a cambio de la restitución patrimonial, arrojando un rosario de casuística en lo que al matrimonio se refiere que merece ser estudiada con detenimiento en otro trabajo. Para el surgimiento y desarrollo, véase, entre otras obras, Vogel, Cyrille, Le pécheur et la pénitence au Moyen Age, (Paris, 1969) = ACHILLE Cesarini, Clara, Il peccatore e la penitenza nel medievo, (1969, trad. Cast. Leumann, 1988).

${ }^{104}$ Poenitentiale Theodori, L. II, can. XII (De Questibus Conjugiorum), en Councils and Ecclesiastical Documents relating to Great Britain and Ireland, HadDAN Arthur West-STUBBS, William, (Oxford, 1871), III, pp. 199-201. 
contraer un nuevo matrimonio, si se trataba de la primera unión, -secundum Grecos- siempre que no hubiese sido matrimonio canónico; si, por el contrario, era una segunda unión, no podían contraer nuevas nupcias vivente "viro vel uxore": "Potest tamen alter alteri licentiam dare accedere ad servitutem Dei in monasterium et sibi nubere, si in primo conubio erit, secundum Grecos; et tamen non est canonicum; sin autem in secundo, non licet vivente viro vel uxore. Maritus si se ipsum in furtu aut fornicatione servum facit vel quocunque peccato, mulier si prius non habuit conjugium, habet potestatem post annum alterum accipere virum; digamo non licet ${ }^{105}$ ".

Si la mujer se separaba del marido despreciándolo, y no quería volver con él, pasados cinco años, con el consentimiento del obispo, podía casarse con otra mujer: "Si mulier discesserit a viro suo despiciens eum, nolens revertere et reconciliari viro, post $V$. annos cum consensu Episcopi aliam accipere licebit uxorem" 106.

Si la esposa había sido llevada al cautiverio por la fuerza, el marido podía tomar otra esposa después de un año, siempre que no pudiera ser rescatada: "Si in captivitatem per vim ducta redimi non potest, post annum alteram accipere" 107 . Del mismo modo, si la mujer fuese reducida a esclavitud, después de 5 años, podía volver a casarse. Lo mismo había de entenderse en el caso de la mujer: "Item si in captivitatem ducta fuerit, vir ejus $V$. annos expectet; similiter autem et mulier si viro talia contingerint" ${ }^{108}$. Debían, eso sí, abandonarla cuando el primer cónyuje fuera liberado: "Si igitur vir alteram duxerit uxorem, priorem de captivitate reversam recipiat, posteriorem dimittat: similiter autem illa, sicut superius diximus, si viro talia contingerint, faciat" ${ }^{109}$.

Si el enemigo se llevaba a la mujer, y no le era posible alcanzarla, podía contraer nuevas nupcias: "Si cujus uxorem hostis abstulerit, et ipse eam iterum adipisci non potest, licet aliam accipere; melius est sic facere quam fornicationes" $" 110$. Si una vez desposado nuevamente, la primera esposa volvía, no estaba obligado a tomarla nuevamente si ya había tomado otra. Ella misma podía tomar otro marido, si sólo había tenido uno con anterioridad: "Si iterum post haec uxor ilia venerit ad eum, non debet recipi ab eo, si aliam habet; sed illa tollat alium virum sibi, si unum ante habuerat. Eadem sententia stat de servis transmarinis ${ }^{111 " .}$

Por último, en caso de impedimentos secretos, aunque ya estuvieran unidos en matrimonio, si la mujer manifestaba que su marido no podía casarse con ella, y se demostrase la vercidad de la acusación, ella podía casarse con otro hombre. "Si vir et mulier conjunxerint se in matrimonio, et postea dixerit mulier de viro, non posse nubere cum ea, si quis poterit probare quod verum sit, accipiat alium"112.

Otro de ellos será el penitencial de Burcardo de Worms (1008-1012): "Contigit tibi ut uxor tua te conscio et hortante cum alio viro, illa autem nolente adulterium

\footnotetext{
${ }^{105}$ Can. 8.

${ }^{106}$ Can. 19.

${ }^{107}$ Can. 20.

${ }^{108}$ Can. 21.

${ }^{109}$ Can. 22.

${ }^{110}$ Can. 23.

${ }^{111}$ Can. 24.

${ }^{112}$ Can. 32.
} 
perpetraret? Si fecisti, XL dies, id est, carinam, in pane et aqua poeniteas et septem annos, unum ex his in pane et aqua poeniteas, et nunquam sis sine poenitentia. Si auter uxor tua hoc probare potuerit, quod tua culpa et tuo jussu, se renuente et reluctante, adulterata sit, si se continere non potest, nubat cui voluerit, tantum in Domino. Tu autem sine uxoria spe in perpetuo permaneas. Illa autem si consentiens fuerat, eadem jejunet quae tibi proposita sunt, et sine spe conjugii permaneat" ${ }^{\prime 13}$.

Para algunos estudiosos, esta actitud frente al cónyuge inocente demuestra que no se puede considerar de la misma manera a uno que a otro: si bien se apela a la recta conciencia en el proceder (delante del Señor). Nuevamente, podemos seguir trazando una línea en la que la Iglesia considera de modo especial a determinadas víctimas, sea por actitud humana (adulterio) sea por mal sobrevenido (lepra) ${ }^{114}$.

En general, muchos penitenciales recogerán actitudes semejantes, volviendo casi siempre a los motivos que antes detallábamos ${ }^{115}$. A su vez, entre los pontífices de aquel milenio es posible encontrar soluciones semejantes ${ }^{116}$. Gregorio II (715-731) respondía a una pregunta del Obispo de Maguncia, S. Bonifacio, de este modo: "Nam quod posuisti, quodsi mulier infirmitate correpta non valuerit viri, debitum reddere, quid eius faciat iugalis: bonum esset, si sic permaneret, ut abstinentiae vaceret; se, quia hoc maiorum est, ille, qui se non poterit continere, nubat magis. Non tamen subsidii open subtrahat ab illa, cui infirmitas praepedit et non detestabilis culpa excludit"117.

Esteban II, poco tiempo después, mantendrá una postura similar: "si quis se in conjugio copulaverint, et ni eorum contigerit ut debitum reddere non possit, non liceat eos separare: nec pro alia infirmate, excepto si demonii infirmitas, aut leprae macula supervenerit. caeterum si ab his duabus infirmitatibus liberi fuerint invicem conjuncti unus alteri servitutum exhibeat" 118 .

Sin embargo, no dejan de ser posturas aisladas y, poco a poco, como decíamos, acabará por terminar de imponerse la más generalizada de los concilios universales,

${ }^{113}$ Burchardus Vormatiensis, Decretorum libri viginti, L. XIX, en Migne, Patrologia Latina 140, col. 959.

${ }^{114}$ Cfr. Picasso, Giorgio, (a cura di), A pane e aqua. Peccati e penitenze nel Medioevo. Il Penitenziale di Burcardo di Worms, Europia, (Novara, 1986), p. 44. Trad. de Botero Giraldo, José Silvio.

${ }^{115}$ Antonio García y García afirma que la mayor parte de los penitenciales admiten el divorcio vincular y el paso a un segundo matrimonio viviendo aún el primer consorte, por una serie de causas (Cfr. GARCíA Y GARCíA, Antonio, La indisolubilidad matrimonial en el primer milenio, con especial referencia a los textos divorcistas, en GARCía BARBERENA, Tomás, El vínculo matrimonial ¿Divorcio o indisolubilidad?, (Madrid, 1979), pp. 117-164, esp. p. 148.

${ }^{116}$ El papa León ya se había pronunciado en el caso de un prisionero de guerra que vuelve luego de mucho tiempo y encuentra que su mujer se ha casado nuevamente. El papa admite que el primer marido pueda renunciar voluntariamente a sus derechos (Carta 159 a Nicetas de Aquileia, en Migne, Patrologia Latina 54, 1136-1137).

117 Cfr. Mon. Germ. Hist., Epist. III, 276. Gregorius II Pp., Ep. Ad varias Bonifatii consultationes, en Monumenta Germaniae Historica, Epistolarum Tomus III (Merowingicii et Karolini Aevi I), p. 276.

${ }^{118}$ Kelly, William, Pope Gregory II on divorce and remarriage: a canonical-historical investigation of the letter Desiderabilem mihi, with special reference to the response Quod proposuisti (Roma, 1976), p. 72. 
que también estará presentes en los concilios locales: "Las de tendencia centrífuga universalizante (colecciones dionisiana, hispana, hadriana, dackeriana...) que afirman el vínculo indisoluble; y las de tendencia centrípeta o particularizante, más ajurídicas (colecciones penitenciales, anglosajonas...), que derivan en posibles disoluciones matrimoniales por las causas romanas y después germánicas de adulterio, abandono, amencia, cautiverio, impotencia, esclavitud, ingreso en religión" ${ }^{119}$.

\section{EPÍLOGO}

Después de repasar los textos conciliares y las fuentes canónicas que contemplan de algún modo las excepciones a la hora de admitir a los sacramentos a los concubinos, podemos concluir que, si bien la posibilidad de $s$ e g u n d a s n u p c i a s, o del reconocimiento de nuevas uniones, o al menos de la ausencia de un castigo, en un comienzo, aun en el caso de los viudos, no era admitida, también lo es que gradualmente se fue permitiendo, y, con el paso del tiempo, se adoptó una postura de benignidad, que en primer lugar partía de causas como el adulterio para ir poco a poco contemplando algunas otras: la vida monástica, el riesgo de pecado inminente ante la imposibilidad de la incontinencia, la edad, el sexo, etc.

La postura oficial seguirá siendo en todo caso la de la indisolubilidad, desde un punto de vista teórico, y sin definiciones dogmáticas, lo que abrirá la puerta a que se puedan aplicar soluciones pastorales de urgencia que se anclarán en el texto de Mateo (la célebre porneia) y en leyes civiles permisivas o contrarias. En cualquier caso, pese a la claridad de la doctrina, durante todo el primer milenio vemos como la Iglesia aborda un problema candente de la sociedad de cada momento, intentando dar una respuesta adecuada a las inquietudes de la misma.

De hecho, como hemos visto, en no pocas ocasiones, pese a la unidad de la postura dogmática, los pastores eran conscientes de la dificultad de cumplir con ella en un ambiente poco favorable, lo que ha sido interpretado por algunos como un reconocimiento de las segundas nupcias como la opción menos mala, aunque nunca recomendable ${ }^{120}$. En este sentido, si bien es cierto que no son tantos los textos en los que se pueden encontrar dichas excepciones, ni son especialmente claros muchos de ellos, y compartiendo que la Iglesia no puede basar su praxis en "hipótesis exegéticas discutidas"121, es precisamente esa falta de claridad la que demuestra la complejidad del tema tratado ${ }^{122}$. Desde nuestro punto de vista, al margen de las interpretaciones que se hayan hecho recientemente de dichos textos,

${ }^{119}$ RoDríguez DíEz, José, Indisolubilidad y divorcio en la historia del matrimonio cristiano y canónico ¿Indisolubilidad extrínseca relativa de futuro?, en Anuario Jurídico y Económico Escurialense, 39 (2006), pp. 171-214. Así, los concilios de Friuli (a. 796, can. 10), de París (a. 829, can. 2), de Nantes (a. 895, can. 12), Triburiense (a. 895, can. 46).

${ }^{120}$ Botero Giraldo, José Silvio, El cónyuge injustamente abandonado. Una situación que reclama justicia" en Teología y Vida, 54 (2004), pp. 3-17.

${ }^{121}$ MÜLLER, Gerhard Ludwig, La forza della grazia. Indissolubilità del matrimonio e dibattito sui divorziati risposati e i sacramenti, en L'Osservatore Romano (23 ottobre 2013), pp. 4-5, esp. p. 5.

${ }^{122}$ TARANZANO, Adrián, ¿Se disuelve la indisolubilidad matrimonial? Consideraciones acerca del debate en torno al próximo Sínodo, en Teología: Revista de la Facultad de Teología de la Pontificia Universidad Católica Argentina, 115 (2014), pp. 185-213, esp. p. 189. 
y sin querer caer en una escasamente científica fundamentación que permita, porque sí, que la Iglesia contemporánea liberalice su actitud hacia los divorciados vueltos a casar, consideramos que calificar simplemente de abusos tales excepciones sería realizar un análisis contextual que altera el punto de vista histórico: del mismo modo que es absurdo hablar de mentalidad divorcista en la época conciliar antigua, tampoco tiene sentido calificar como simples traidores a la Tradición (o de contaminados a los textos recibidos) a quienes aplican, con más o menos fortuna, soluciones pastorales a la grey que se les ha encomendado. Debemos darnos cuenta que, si bien nuestro tratamiento actual del problema responde a la regulación germinada en Letrán y florecida en la lógica de Trento (convocado para un mundo cristiano, acaso no católico, pero siempre cristiano, y que debía defenderse de un enemigo que trataba de imponer su propia doctrina), hoy día nos encontramos más bien en una ambiente pre-nicénico, cuando la Iglesia convivía con un Imperio ora indiferente, ora hostil, y al que sabía que estaba llamado a convertir, más aún, al que debía hacer consciente de su necesidad de salvación.

Así, ante la ausencia de una regulación canónica del matrimonio, los concilios locales antiguos, perfectamente conocedores de la realidad particular y del contexto concreto al que se enfrentan, recurrieron a determinadas situaciones de excepción para evitar el abandono de los fieles que pudieran encontrarse en situaciones teóricamente irregulares. Algunas de las excepciones que hemos visto, tales como la cuestión de los secuestros o la lepra, si bien no son trasladables a la realidad actual, sí demuestran cómo la Iglesia ha sido capaz de aplicar medidas que pueden parecer escandalosas a casos en los que no es el pecado la causa de la situación irregular. Por ello, en ocasiones excepcionales, el concubinato-entendido como una situación en la que son las formalidades legales y las circunstancias socio-jurídicas las que impiden la unión matrimonial- es reconocido como una auténtica unión, siempre que no se deba al rechazo personal a los elementos esenciales de la institución matrimonial. 